
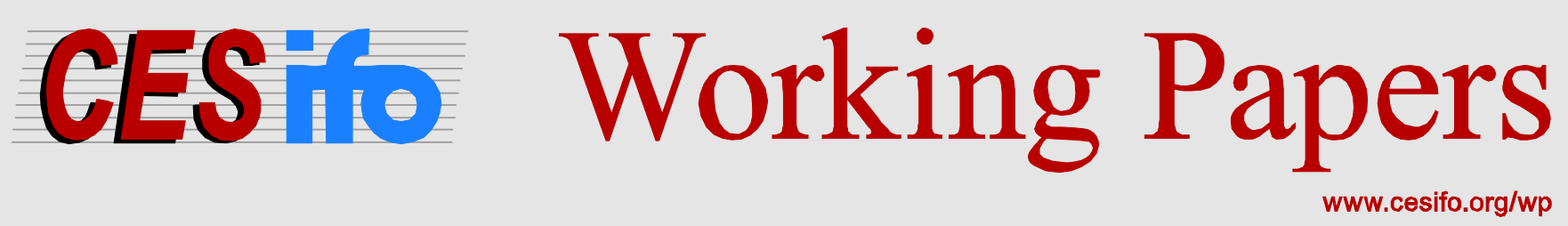

\title{
Emergent Dynamics of a Macroeconomic Agent Based Model with Capital and Credit
}

\author{
Tiziana Assenza \\ Domenico Delli Gatti \\ Jakob Grazzini
}
CESIFO WORKING PAPER NO. 4765
CATEgORY 7: MONETARY POLICY AND INTERNATIONAL FinANCE
APRIL 2014

Presented at CESifo Area Conference on Macro, Money \& International Finance, February 2014

An electronic version of the paper may be downloaded

- from the SSRN website:

WWW.SSRN.cOm

- from the RePEc website:

www.RePEc.org

- from the CESifo website:

www.CESifo-group.org/wp 


\title{
Emergent Dynamics of a Macroeconomic Agent Based Model with Capital and Credit
}

\begin{abstract}
Building on the framework put forward by Delli Gatti et al. 2011, in this paper we present and discuss a Macroeconomic Agent-Based Model with Capital and Credit (hereafter CCMABM). The novelty of this model with respect to the previous framework consists in the introduction of capital goods that firms producing consumption goods (C-firms) purchase from capital goods producers (K-firms). The introduction of durability (in the form of capital which depreciates gradually) has important consequences for the emergent macrodynamic behavior. The present CC-MABM is essentially a two-sector macro ABM. In a stylized supply chain the upstream sector, consisting of firms producing capital goods (K-firms) supply a durable and sticky input (capital) to the downstream sector consisting of firms producing consumption goods (C-firms) to be sold to households. Both C-firms and K-firms resort to bank loans to satisfy their financing needs. There are two-ways feedbacks between markets and sectors which yield interesting emerging properties at the macro level.
\end{abstract}

JEL-Code: E320.

Keywords: agent-based macroeconomics, capital, credit, crisis, upstream, down-stream.

\author{
Tiziana Assenza \\ Department of Economics and Finance \\ Catholic University of Milan \\ Milano / Italy
}

\author{
Domenico Delli Gatti \\ Department of Economics and Finance \\ Catholic University of Milan \\ Milano / Italy \\ domenico.delligatti@unicatt.it
}

\author{
Jakob Grazzini \\ Department of Economics and Finance \\ Catholic University of Milan \\ Milano / Italy
}

First Draft: July, 2013

This Draft: March, 2014

We would like to thank for insightful comments and criticisms the participants to the following conferences: "Computing in Economics and Finance”, Vancouver, July 10-12, 2013; “Symposium CeNDEF @15”, University of Amsterdam, October 24-25, 2013; "First Bordeaux Workshop on Agent-Based Macroeconomics”, Université Montesquieu Bordeaux IV, Bordeaux, November 7-8, 2013; “OFCE-SKEMA-GREQAM Workshop on Agent-Based Macroeconomics”, SKEMA Business School, Sophia-Antipolis, Nice, November 22, 2013; "Complexity Seminar series”, Tinbergen Institute, Amsterdam, February 5, 2014, "CESIFO Area Conference on Macro, Money and International Finance”, February 21-22 2014. The usual caveat applies. Financial support from the EU 7th FP project “Complexity Research Initiative for Systemic InstabilitieS (CRISIS)", grant no. 288501 is gratefully acknowledged. 


\section{Introduction}

In this paper we present and discuss a Macroeconomic Agent-Based Model (hereafter MABM) with capital and credit (CC-MABM). Our starting point is the MABM developed in Delli Gatti et al. 2011, in which there are only consumption goods produced by means of labor only. Such a framework is inadequate when one wants to replicate empirical business cycle facts because changes in capital and in inventories play a major role in shaping the dynamic patterns of GDP over the business cycle. The first reason why we want to move up the ladder of complexity in macroeconomic model building, therefore is simply realism, i.e. the need to reproduce as much as possible macroeconomic reality.

The introduction of capital and investment, moreover, goes hand in hand with a more sophisticated and convincing interpretation of joint investment and financing decisions. Decisions concerning investment in new capital goods and decisions concerning the capital structure of the investing firm, in fac, are deeply interrelated.

The present CC-MABM is essentially a two-sector macro ABM. In a stylized supply chain the upstream sector, consisting of firms producing capital goods (K-firms) supply a durable and sticky input (capital) to the downstream sector consisting of firms producing consumption goods (C-firms) to be sold to households. Both C-firms and Kfirms resort to bank loans to satisfy their financing needs. There are two-ways feedbacks between markets and sectors which yield interesting emerging properties at the macro level. In particular, the interaction of upstream and downstream firms and the evolution of their financial conditions may generate a "crisis", i.e. a long slump followed by a steep recovery.

The paper is organized as follows. Section 2 discusses the related literature, section 3 presents the basic features of the economic environment. Sections 4 presents the behavioral assumptions concerning households (workers and capitalists/rentiers). Sections 5 and 6 present the behavioral assumptions concerning firms in the C-sector and in the K-sector respectively. In section 7 we discuss the determination of the financing gap and of the demand for loans on the part of firms. In section 8 we present the determination of the interest rates and of the supply of loans on the part of the banking system. Section 
9 is devoted to a discussion of the results of the simulations. Section 10 concludes.

\section{Related literature}

Toy models in which the only final use of goods is consumption and the only input is labour are easier to interpret and sometimes sufficient to answer deep research questions but they are surely inadequate when one wants to replicate stylized empirical business cycle facts. As it is well known, in fact, changes in capital and in inventories play a major role in shaping the dynamic patterns of GDP over the business cycle. Realism, therefore, may be invoked to move from simpler to more sophisticated models where capital and investment play a relevant role.

A second and no less important motivation to complexify models is that the financing decisions of firms enter into the picture in a significant way only when investment is considered. The balance sheet of the firm is, in this case, properly defined: capital and liquidity show up in the assets side, external finance (debt) on the liabilities side and equity or net worth is defined as the difference between the two. Investment decisions and decisions concerning the capital structure of the firm are typically interrelated. This need to move up in the ladder of increasing complexity of the model is evident both in New Keynesian-DSGE and in AB models. ${ }^{1}$

In the NK-DSGE literature, the canonical three equations model popularized by Clarida, Gali' and Gertler (1999) in which there are only consumption goods, the only input is labor and financing decisions are absent has been superseded by more sophisticated models with capital and financial frictions starting from Bernanke-Gertler-Gilchrist, 1999 (hereafter:BGG). A large literature has developed from this pioneering paper. A couple of recent and remarkable additions to this literature are Christiano-Motto-Rostagno, 2010 (CMR), Gertler-Kiyotaki,2010 (GK).

In BGG (i) "entrepreneurs" (or wholesale goods producers) use capital and labour to produce and sell a homogeneous good to "retailers", (ii) retailers differentiate the good and sell final goods to households (in the form of consumption goods) or to capital pro-

\footnotetext{
${ }^{1}$ The remark applies only partially to Real Business Cycle models, whose skeleton is a stochastic growth model where capital is playing a key role by construction. Financing decisions, however, are generally overlooked in relatively simple RBC models.
} 
ducing firms (K-firms) (in the form of investment goods), (iii) K-firms use investment goods and undepreciated capital (sold by entrepreneurs to K-firms) to produce and sell new capital to the entrepreneurs.

In CMR the architecture is even more complex: (i) intermediate goods firms use capital and labour to produce and sell differentiated goods to final goods producers, (ii) final goods producers in turn sell final goods to households (consumption goods) and to Kfirms (investment goods), (iii) K-firms use investment goods and undepreciated capital to produce and sell new capital to the entrepreneurs, (iv) finally entrepreneurs rent capital to intermediate goods producers. As far as financing decisions are concerned, both in BGG and in CMR entrepreneurs ask for loans to financial intermediaries in order to finance the difference between the cost of investment and internal resources (net worth). In GK, this part of the architecture is streamlined: (i) final goods producers use capital and labour to produce and sell undifferentiated final goods to households (consumption goods) and to K-firms (investment goods), (ii) K-firms use investment goods and undepreciated capital to produce and sell new capital to the final goods producers. As far as financing decisions are concerned, final goods producers ask for loans to financial intermediaries in order to finance the difference between the cost of investment and internal resources (net worth).

There are different ways of modelling capital also in the AB literature. For instance, in the EURACE framework (Cincotti et al. (2010), Dawid et al. (2011)) final goods producers use capital goods (supplied by K-firms) characterized by different qualities/productivities and hire workers characterized by different skills to produce and sell consumption goods to households. The use of high quality capital goods requires the employment of skilled workers, hence qualities of capital goods and skills of workers are complements in production. Moreover, the technological frontier in the production of capital goods is pushed up systematically over time by a stochastic (innovation) process.

Along similar lines, in the Keynes meeting Schumpeter $(K m S)$ framework, Dosi et al. (2010) assume that consumption goods producers use labour and machine tools (supplied by K-firms) to produce and sell consumption goods to households. Machine tools are characterized by different productivities. K-producers, in fact, spend resources in 
$\mathrm{R}$ and $\mathrm{D}$ to discover new products and increase the productivity of the machines they produce. In both the EURACE and the KmS frameworks, embodied technical progress plays a key role in driving fluctuations and (long run) growth in the model.

The model we discuss in the present paper may be considered a simpler and shorter route to introduce capital and investment in a MABM. In our model capital goods (and labour) are not differentiated: the productivity of labour and of capital is uniform across workers and firms respectively. In particular K-firms do not engage in R and D activity and therefore technical progress does not trickle down in the macroeconomy through machine tool purchases on the part of final goods producers. The reason for this simpler approach is in itself simple: we want to explore only the role of capital - characterized as a durable and sticky input - in shaping gdp fluctuations at business cycle frequency. We are not interested (for the moment) in modeling the changes in gdp at low frequencies. Thanks to this different research question, we end up with a much leaner architecture: in a stylized supply chain K-firms play the role of upstream suppliers of a durable and sticky input (capital) to C-firms, who play the role of downstream customers of K-firms and suppliers of consumption goods to households. Both C-firms and K-firms resort to bank loans to fill their financing gap. This modeling approach has remarkable repercussions on the properties of the business cycle as we will see in the section on simulations.

\section{The Model}

We consider an economy populated by households, firms and banks.

The household sector consists of workers and "capitalists". Workers supply labor and buy consumption goods. Capitalists are the owners of firms (for simplicity we assume that there is one capitalist per firm). They get dividends and buy consumption goods (therefore they behave as rentiers). Both workers and capitalists save and accumulate financial wealth in the form of deposits at banks.

The corporate sector consists of producers of consumption goods (C-firms) and producers of capital goods (K-firms). C-firms demand labor and capital goods in order to produce and sell consumption goods to households. For simplicity we assume that K-firms do 
not need durable inputs: they demand only labor in order to produce and sell capital goods to C-firms. Technology, however, is linear in both cases: in the C-sector, capital and labor are perfect complements (Leontief production function); in the K-sector the productivity of labor is given and constant. Hence total cost is linear in production and marginal cost is given and constant.

If internal financial resources are not sufficient to finance costs firms resort to bank loans to fill the financing gap.

Banks receive deposits from households and extend loans to firms. For the sake of simplicity, we reduce the cardinality of the set of banks to one. ${ }^{2}$ Households' deposits are not remunerated. As to loans, the bank has to decide both the price (interest rate) and the quantity of credit to be extended to each borrowing firm. The bank will provide funds on demand (up to a maximum amount) to each firm at an interest rate which is different from one borrower to another depending on the firm's financial fragility.

There are markets for consumption goods, capital goods, labor, credit and deposits. The markets for goods and labor are characterized by a search and matching mechanism. ${ }^{3}$ We assume that on the markets for goods and labor neither sellers nor buyers have complete information about business conditions, e.g. posted prices and available quantities. They incur transaction costs to explore the market and therefore engage in local interaction with a finite set of potential trading partners. Each consumer (worker, capitalist) visits a random sample of C-firms, ranks them in ascending order of price and demands C-goods starting from the firm who has posted the lowest price. This search and matching mechanism implies that firms charging lower prices will receive larger orders and will be more likely to find buyers. A similar mechanism is at work also in the market for capital goods. Each C-firm selects at random a set of K-producers, ranks them in ascending order of price and demands capital goods starting from the firm who has posted the lowest price.

Both C-firms and K-firms have market power on their local market. In the present framework, this is due to transaction costs which force buyers to visit only a limited

\footnotetext{
${ }^{2}$ This simplifying assumption can be easily relaxed. In Delli Gatti et al. 2011, for instance, there is a finite set of banks.

${ }^{3}$ Since we have assumed that there is only one bank, the credit and deposits markets are the only markets which are not modeled by means of a search and matching mechanism.
} 
number of sellers so that goods, in the buyers' eyes, are imperfect substitutes even if they are not differentiated. ${ }^{4}$

Thanks to market power, each firm behaves as a monopolist on her own local market. If the firm knew the demand curve, she would choose an optimal mark up (i.e. ratio of the individual price to marginal cost) and an optimal scale of activity, profits would be maximized and demand would be always equal to supply. We assume, however, that the firm does not know the demand curve so that she cannot choose her mark up optimally. Since technology is linear, however, once the firm has chosen the price (and therefore the mark up) she will try to maximize output, the only constraint being the demand for her good. ${ }^{5}$ She may end up, however, with an inventory of unsold goods - if she has overestimated demand - or a queue of unsatisfied consumers (if demand has been underestimated). Both situations are costly for the firm, so that we can assume that the firm is always adapting to market conditions in order to minimize the distance between production and demand. Moreover, due to implicit Bertrand competition, she will also try to minimize the distance between her own price and the average price charged by competitors.

On the labor market firms post vacancies and unemployed workers visit a random sample of firms in search of a job. For simplicity, in this paper we assume that the wage posted is constant and uniform across firms. ${ }^{6}$ As a consequence unemployed workers do not rank firms and stop searching whenever a matching opportunity emerges, i.e. when a firm they visit has posted a vacancy.

Notice that in the markets considered so far (labor and goods) in each period the searching agent selects at random a new set of potential trading partners . Consumer $C_{1}$, for instance, may visit firms $F_{1}$ and $F_{4}$ today and firms $F_{2}$ and $F_{5}$ tomorrow. Therefore there is no "brand loyalty" which links a specific consumer to a specific firm in a sort of implicit partnership. The network of transactions (if any) generated by this mechanism

\footnotetext{
${ }^{4}$ Of course we could assume that market power is due to product differentiation - as in the standard Dixit-Stiglitz model of monopolistic competition.

${ }^{5}$ In so doing, the firm behaves as a myopic optimizer (she is indeed doing her best to maximize profits period by period).

${ }^{6}$ This is of course a simplifying assumption. In Delli Gatti et al. 2011, for instance, each firm offers a wage consisting of (i) a uniform minimum wage which is indexed to inflation and may capture the effect of nationwide collective bargaining and (ii) a firm-specific component which is increasing with the number of vacancies posted.
} 


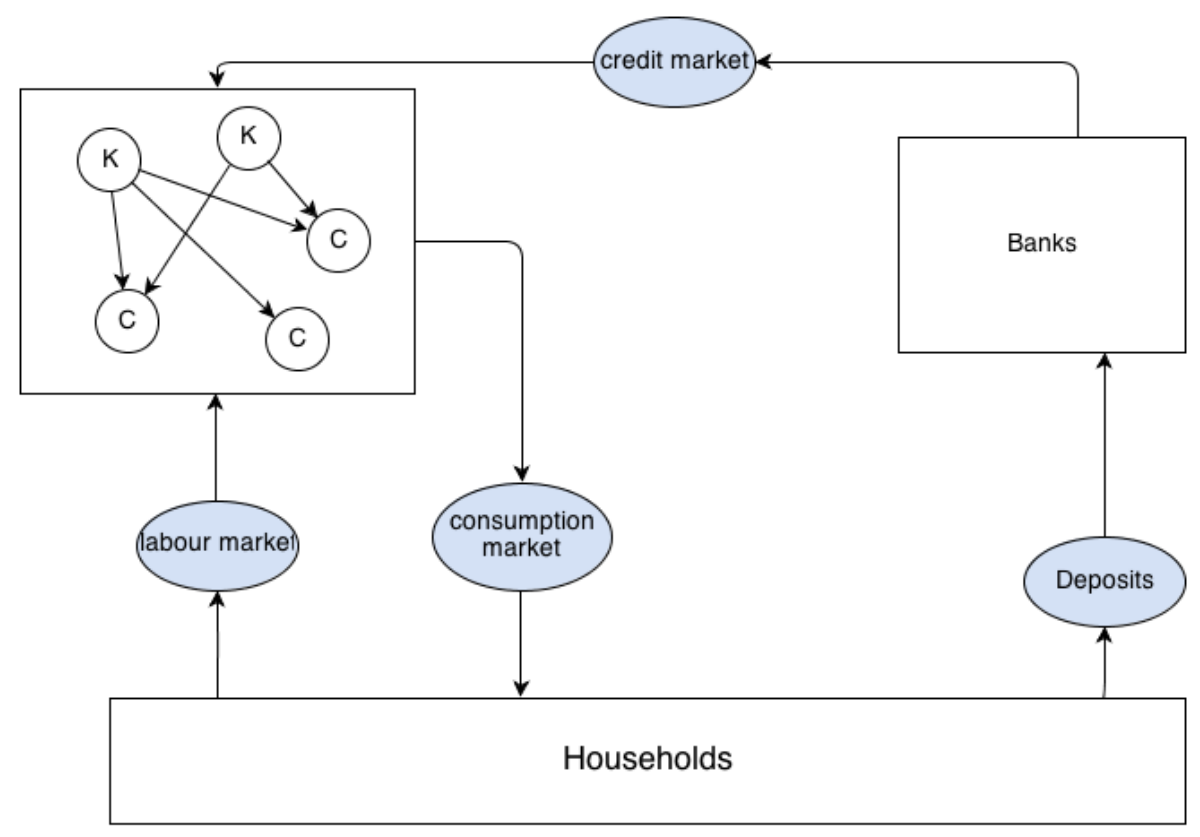

Figure 1: The macroeconomy: agents and markets

is reshuffled every period. Due to search and matching and local interaction, on the market for C-goods and K-goods unsold goods at some firms may coexist with queues of unsatisfied customers at some other firms. Moreover, some households may end up spending less than planned and accumulating involuntary saving. On the labor market redundant labor force at some firms and unemployment may coexist with unfilled vacancies at other firms. Figure 1 presents a visualization of the macro-economy.

\section{Households}

The household sector consists of workers and capitalists.

\subsection{Workers}

Workers play a role as suppliers on the the labor market and as consumers on the Cmarket.

The $h-t h$ worker $(h=1,2, \ldots, H)$ supplies inelastically one unit of labor.

If unemployed the worker looks for a job on the labor market by visiting $Z_{e}$ firms chosen at random and applying to those with open vacancies. Since the posted wage is given and uniform across firms, the unemployed worker will accept a job from the first firm with 
open vacancies he has the chance to visit. If he doesn't find a vacancy to fill, he remains unemployed and will fund his consumption (see below) dis-saving, i.e. consuming out of accumulated wealth.

If he succeeds in finding a job, he will receive the wage $w$ until he is fired. For simplicity we assume that there are neither hiring nor firing costs. ${ }^{7}$ If a firm wants to scale down activity in a certain period, she can fire workers at no costs. Fired workers become unemployed and start searching for a job in the same period.

\subsection{Capitalists}

For simplicity, we assume that each firm (both in the C-sector and in the K-sector) is owned by a capitalist. There are therefore as many capitalists as there are firms, say $F{ }^{8}$ Each capitalist receives income in the form of dividends if the firm he owns is making profits after interest payments. Dividends accruing to the f-th capitalist are defined as $\tau \pi_{f, t-1}$ where $\tau \in(0,1)$ is the dividend payout ratio and $\pi_{f, t}$ are profits. If the firm makes losses that deplete her net worth, she will go bankrupt and be replaced by a new firm. In this case we assume that the owner of the bankrupt firm employs his personal wealth to provide equity to the entrant firm. In other words, the capitalist is de facto re-capitalizing the defaulting firm to make her survive. Each firm is therefore a dynasty and the number of firms is constant. ${ }^{9}$

\footnotetext{
${ }^{7}$ This simplifying assumption can be easily relaxed. The presence of hiring and firing costs would reduce labor mobility and lead to labor hoarding. We leave the exploration of this issue to future research.

${ }^{8} F=F_{c}+F_{k}$ where $F_{c}$ is the number of C-firms and $F_{k}$ is the number of K-firms.

${ }^{9} \mathrm{By}$ splitting the household sector into workers and capitalists, we have simplified the problem of firms' ownership, dividend distribution and recapitalization of defaulting firms to the greatest possible extent. As an alternative, we could have maintained that households supply labor and own firms at the same time. This alternative assumption, however, would have posed the problem of attributing ownership rights, dividends and recapitalization commitments to heterogeneous households.
} 


\subsection{Consumers}

In the $\mathrm{C}$-market, workers and capitalists together behave as $\mathrm{F}+\mathrm{H}$ consumers. In each period the c-th consumer receives income $Y_{c, t}$ where

$$
Y_{c, t}= \begin{cases}w & \text { if the consumer is a worker with an active labor contract } \\ \tau \pi_{f, t-1} & \text { if the consumer is a capitalist receiving dividends }\end{cases}
$$

On the basis of current income, the consumer computes human wealth as follows $\bar{Y}_{c, t}=$ $\xi \bar{Y}_{c, t-1}+(1-\xi) Y_{c, t}$ where $\xi \in(0,1)$ ia a memory parameter. By iterating it is easy to see that human wealth is a weighted average of current and past incomes with exponentially decaying weights. Human wealth is a proxy for future expected income. In this interpretation, the consumer forms expectations of future income using an adaptive mechanism. Finally, the consumer determines the budget allocated to consumption as follows: $C_{c, t}=\bar{Y}_{c, t}+\chi D_{c, t}$ where $D_{c, t}$ is the consumer's non-human (i.e. financial) wealth (deposited at the bank) and $\chi \in(0,1)$ is the fraction of wealth used in consumption.

This simple rule of thumb which characterizes consumer behavior in a bounded rationality setting is reminiscent of the original permanent income/life cycle hypothesis. ${ }^{10}$ If the consumer does not receive income - for instance because a worker becomes unemployed or a capitalist does not receive dividends - he will de-cumulate his financial wealth to form a consumption budget. The c-th consumer's financial wealth (deposits), therefore, is $D_{c, t}=D_{c, t-1}+Y_{c, t}-C_{c, t}$ Once they have determined their consumption budget, consumers visit C-firms in order to purchase goods. The h-th consumer visits $Z_{c}$ randomly selected firms, ranks them in ascending order of posted price and demands

\footnotetext{
${ }^{10} \mathrm{As}$ it is well known, inter-temporal optimization and rational expectations yield the following results: (i) current consumption is equal to permanent income, (ii) permanent income is proportional to the sum of financial wealth and human wealth; human wealth in turn is defined as the present value of future expected incomes,(iii) the coefficient of proportionality (of permanent income to cash on hand) is a function of the real interest rate and the rate of time preference; under some restrictions it coincides with the real interest rate. The interpretation is straightforward: consumption is equal to the annuity value of total (financial and human) wealth, i.e. permanent income. A rough approximation of this coefficient, determined in an inter-temporally optimal way, is something around 5 per cent. Carroll $(1992,1997,2009)$ has shown that in the presence of uncertainty about future labor incomes and precautionary savings, consumption is a concave function of cash-on-hand i.e. the sum of human capital and beginning of period wealth (Deaton, 1991)In Carroll's framework, for low values of wealth, the propensity to consume (out wealth) is quite high due to the precautionary saving motive: a reduction of wealth would in fact lead to a steep reduction of consumption to rebuild wealth.
} 
consumption goods starting from the firm charging the lowest price. If he does not exhaust the consumption budget at the lowest price firm, he will move up to the second firm in the ranking and so on. If he exhausts the purchasing opportunities (i.e. the visits to the $Z_{c}$ firms) without exhausting the consumption budget, he will save involuntarily. Hence, firms posting lower prices are more likely to find customers and will receive larger orders on average. This implies that there is an implicit negative elasticity of the demand for the good produced by the i-th C-firm to the relative price $\frac{P_{i}}{P}$ where $P_{i}$ is the price charged by the i-th firm and $P$ is the average price. Assuming that the individual firm is "negligible", the average price is approximately equal to the price charged by the "competitors". Notice however that both the price elasticity and the absolute level of demand at each price for each C-good are not constant. Firm $F_{1}$, for instance, may be visited by consumers $C_{1}$ and $C_{3}$ today and by consumers $C_{2}$ and $C_{5}$ tomorrow. The search and matching mechanism leads to the coexistence of queues of unsatisfied consumers (involuntary savers) at some firms and involuntary inventories of unsold goods at some other firms.

\section{C-firms}

The i-th firm in the $\mathrm{C}$-sector $\left(i=1,2, \ldots, F_{c}\right)$ produces a C-good using labor and capital. Imperfect information and transaction costs force the firm to explore a limited portion of the price-quantity territory around the current position - the status quo - in order to adapt to the market environment.

At the beginning of time $t$ the i-th firm sets the status quo, i.e. the pair $\left(P_{i, t}, Y_{i, t}\right)$ where $P_{i, t}$ represents the firm's selling price and $Y_{i, t}$ is the firm's current production. At the end of period $t$ the firm learns also the average price $P_{t} \cdot{ }^{11}$ Once production has been carried out and search and matching has taken place the i-th firm can observe actual demand $Y_{i, t}^{d}$. Since sales occur only after the firm has carried out production, actual demand can differ from current production. The difference between current production and actual demand $\Delta_{i, t}=Y_{i, t}-Y_{i, t}^{d}$, if positive, measures involuntary inventories. This is a signal of excess supply (sales are smaller than production), i.e. of a positive forecasting error (in

\footnotetext{
${ }^{11}$ We assume that information concerning the average price is publicly available.
} 
other words demand has been overestimated). For simplicity we assume that C-goods are non storable, hence the firm cannot carry inventories over from today to tomorrow and satisfy future demand. If the firm ends up with a positive inventory she gets rid of the unsold goods at zero costs. ${ }^{12}$

If production in $t$ is smaller or equal to actual demand, i.e. $\Delta_{i, t} \leq 0$ sales are equal to production but there will be a queue of unsatisfied consumers. This is a signal of excess demand, i.e. a negative forecasting error (in other words demand has been underestimated). No inventory accumulation and no queues signal "equilibrium" (hence no forecasting error).

\subsection{Price and quantity decision}

The firm receives two signals: the price charged by competitors and the level of inventories (which reveals forecasting errors). This two signals capture - albeit imprecisely the distance between the firm's actual position (i.e. the status quo) and the situation in which all firms charge the same price and demand equals supply, i.e. $P_{i, t}=P_{t}$ and $Y_{i, t}=Y_{i, t}^{d}$. We refer to this scenario as the benchmark or the "long run equilibrium position". 13 On the basis of this two signals the firm forms expectations on future demand and sets desired production $Y_{i, t+1}^{*}$ at the level of expected demand $Y_{i, t+1}^{e}$, i.e. $Y_{i, t+1}^{*}=Y_{i, t+1}^{e}$. Therefore she decides whether to change the scale of production or the price. 14 Once the direction of change has been decided, the firm has also to decide the magnitude of this change. We assume the firm adopts the following adaptive rule in

\footnotetext{
${ }^{12}$ This assumption simplifies the complexity of the model at the cost of ignoring the role of the inventory cycle in business cycle fluctuations. We leave the exploration of this issue to future research.

${ }^{13}$ In a Dixit-Stiglitz framework in which technology and the elasticity of demand are uniform across firms, Bertrand competition leads to a symmetric Nash equilibrium in which all firms charge the same price, i.e. $P_{i, t}=P_{t}$. In this equilibrium, moreover, each firm produces the same quantity, i.e. a fraction $1 / F$ of total output.

${ }^{14}$ The desired and actual production may be different. Suppose for instance that the firm does not fill all the vacancies or does not get enough credit. In these cases it is impossible to reach desired production, the firm has to scale down activity and actual production is smaller than desired production $\left(Y_{i, t+1}<Y_{i, t+1}^{*}\right)$.
} 
order to change the price:

$$
P_{i, t+1}= \begin{cases}P_{i, t}\left(1+\eta_{i, t+1}\right) & \text { if } \Delta_{i, t} \leq 0 \text { and } P_{i, t}<P_{t} \\ P_{i, t}\left(1-\eta_{i, t+1}\right) & \text { if } \Delta_{i, t}>0 \text { and } P_{i, t}>P_{t}\end{cases}
$$

where $\eta_{i, t+1}$ is a positive parameter drawn from a time invariant uniform distribution with support $(0,0.1)$.

The firm decides to update the expectation of future demand $Y_{i, t+1}^{e}$ and therefore the desired scale of activity $Y_{i, t+1}^{*}$ as follows:

$$
Y_{i, t+1}^{*}=Y_{i, t+1}^{e}= \begin{cases}Y_{i, t}+\rho\left(-\Delta_{i, t}\right) & \text { if } \Delta_{i, t} \leq 0 \text { and } P_{i, t}>P_{t} \\ Y_{i, t}-\rho \Delta_{i, t} & \text { if } \Delta_{i, t}>0 \text { and } P_{i, t}<P_{t}\end{cases}
$$

where $\rho$ is a positive parameter, $\rho \in(0,1)$. Recalling that $\Delta_{i, t}$ is the forecasting error, it is easy to conclude that expected future demand is formed following a simple adaptive rule: $Y_{i, t+1}^{e}=Y_{i, t}^{e}+\rho\left(Y_{i, t}-Y_{i, t}^{e}\right)$. By iterating, it is easy to see that expected future demand is a weighted average of current and past quantities with exponentially decaying weights. If $\Delta_{i, t}<0$, demand is higher than production in $\mathrm{t}$ (the firm has underestimated demand) and the firm revises expected demand and desired production up. On the contrary, if $\Delta_{i, t}>0$, demand is smaller than production (the firm has overestimated demand) and the firm revises expected demand and desired production down. ${ }^{15}$

The firm's position in the price-quantity space is represented in figure 2, where point A represents the benchmark. The firm's position in the price-quantity space at the end of period $t$, given the available information, is described by the status quo. We can partition the plane into four regions $(\mathrm{a}, \mathrm{b}, \mathrm{c}, \mathrm{d})$. The firm will take a price or a quantity decision depending on the region of the plane describing her situation. In particular the firm will change the price if she is in region $a$ or in region $b$ in figure 2 ; she will change the quantity if she is in region $c$ or $d$. In each of the four scenarios the firm changes either the price or the quantity but not both at the same time, i.e. adjustment is partial

\footnotetext{
${ }^{15}$ Actual sales are $Q_{i, t}=\min \left(Y_{i, t}, Y_{i, t}^{d}\right)$
} 


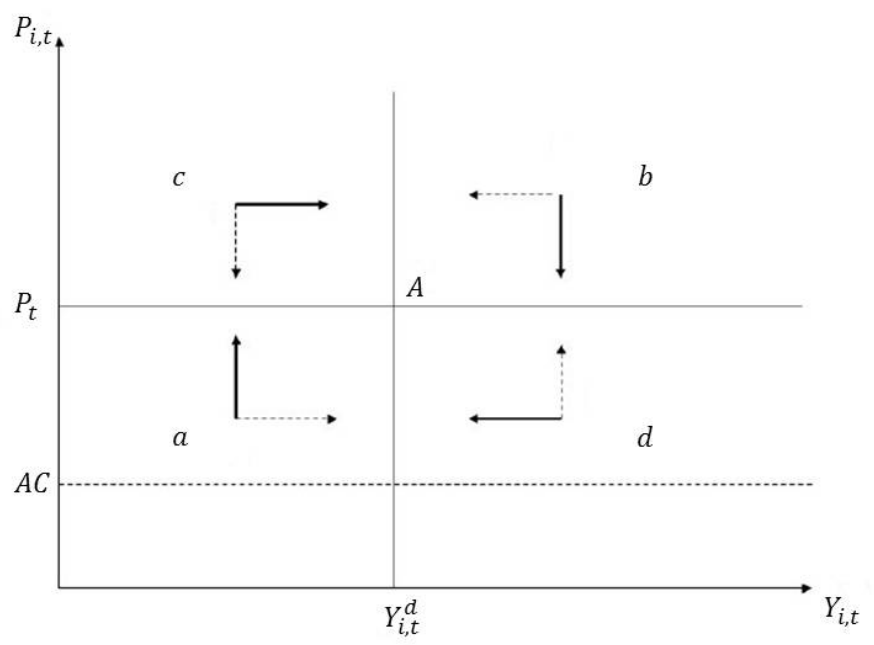

Figure 2: The firm changes either the price or the quantity depending on her position in the price-quantity space.

and asymmetric. ${ }^{16}$ Finally we assume that the firm cannot set the price below a certain threshold ( $A C$ in figure 2$)$ which covers average cost. Moreover, the firm will not choose a quantity below the level that guarantees the employment of at least one worker.

\subsection{Production}

The i-th firm produces output $Y_{i, t}$ by means of capital $K_{i, t}$ and labour $N_{i, t}$. For simplicity we assume a Leontief technology. In a condition of full capacity utilization output will be:

$$
\hat{Y}_{i, t}=\min \left(\alpha N_{i, t}, \kappa K_{i, t}\right)
$$

where $\alpha$ and $\kappa$ are the productivities of labor and capital respectively, both exogenous, constant and uniform across firms. We assume that labor is always abundant, so that $\hat{Y}_{i, t}=\kappa K_{i, t}$. Hence labor requirements at full capacity utilization (i.e. the technically efficient level of employment) is $\hat{N}_{i, t}=\frac{\kappa}{\alpha} K_{i, t}$, where $\frac{\kappa}{\alpha}$ represents the (given and constant) capital/labor ratio.

\footnotetext{
${ }^{16}$ Empirical surveys of managers' pricing and quantity decisions point in this direction, see e.g. Kawasaki et al., 1982; Bhaskar et al., 1993.
} 
When capacity is not fully utilized, only a fraction $\omega_{i, t} \in(0,1)$ of the capital stock will be used in production. $\omega_{i, t}$ represents the rate of capacity utilization. Hence actual production will be:

$$
Y_{i, t}=\omega_{i, t} \hat{Y}_{i, t}=\omega_{i, t} \kappa K_{i, t}
$$

and labor requirement will be $N_{i, t}=\omega_{i, t} \hat{N}_{i, t}=\frac{\kappa}{\alpha} \omega_{i, t} K_{i, t}$.

Physical capital depreciates at the rate $\delta \in(0,1)$. However, only capital which is actually used in production depreciates. Therefore the law of motion of capital installed at the i-th firm is

$$
K_{i, t+1}=\left(1-\delta \omega_{i, t+1}\right) K_{i, t}+I_{i, t}
$$

where $\delta \omega_{i, t+1}$ is the actual depreciation rate and $I_{i, t}$ is investment i.e. the purchase of new capital goods.

\subsection{Investment}

At the beginning of time $t$ the $\mathrm{i}$-th firm has to decide investment $I_{i, t}$. Investment allows the firm to adjust the capital stock. Capital adjustment, however, is costly and time consuming. This is due essentially to two reasons.

First, we assume that only a fraction $\gamma \in(0,1)$ of C-firms is capable to invest (i.e. purchase new capital goods) in each period. This is tantamount to assuming that the probability of investing for each firm is $\gamma$ per period. A simple rationale for this assumption is that there are adjustment costs of the capital stock. ${ }^{17}$

Second, the adjustment process takes time (capital is fixed in the "short run"): new capital goods bought at the beginning of time $t$ will be part of the capital stock only at the end of the same period and therefore will be available in period $t+1$.

Notice that, at the moment of investing in t, the firm's information set is incomplete: she has not observed whether her production decisions in t have produced involuntary

\footnotetext{
${ }^{17}$ It is widely recognized that adjustment costs are a source of stickyness of the capital stock. In the present setting these adjustment costs play the same role as menu costs in Calvo pricing.
} 
inventories or queues. ${ }^{18}$ How does the firm decide how much new capital to buy?

First, the firm computes a the average capital stock used until period t- 1 using the following adaptive rule: $\bar{K}_{i, t-1}=\nu \bar{K}_{i, t-2}+(1-\nu) \frac{Y_{i, t-1}}{\kappa}$ where $\nu \in(0,1)$. By iterating, it is easy to see that $\bar{K}_{i, t-1}$ is a weighted average of past utilized capital with exponentially decaying weights.

Second, the firm forms expectations on the investment needed to replace worn out capital. In so doing, the firm has to take into account the fact that that investment occurs only one period out of four. Therefore investment planned to replace depreciated capital is

$$
I_{i, t}^{r}=\delta \bar{K}_{i, t-1} / \gamma
$$

Third, the firm has to decide the net addition to capital. In order to do so, the firm uses a desired long term rate of capital utilization $\bar{\omega}$. Therefore the capital desired at the investing stage $\mathrm{t}$ for $\mathrm{t}+1$ is $K_{i, t+1}=\bar{K}_{i, t-1} / \bar{\omega}$. Total investment therefore will be

$$
I_{i, t}=K_{i, t+1}+\frac{\delta}{\gamma} \bar{K}_{i, t-1}-K_{i, t}
$$

\subsection{Labor requirement and vacancies}

Let's assume that, on the basis of expected demand, the firm decides to produce $Y_{i, t+1}^{*}$ in $t+1$. Hence desired capital is $K_{i, t+1}^{*}=\frac{Y_{i, t+1}^{*}}{\kappa}$. Given the availability of capital at the same date, $K_{i, t+1}$, there are two scenarios.

If the capital stock is large - i.e. $\kappa K_{i, t+1}>Y_{i, t+1}^{*}$ (or, equivalently, $\left.K_{i, t+1}>K_{i, t+1}^{*}\right)-$ the firm could reach the desired scale of activity by setting capacity utilization at the required level: $\omega_{i, t+1}^{*}=\frac{Y_{i, t+1}^{*}}{\kappa K_{i, t+1}}$. Then desired employment would be $N_{i, t+1}^{*}=K_{i, t+1}^{*} \frac{\kappa}{\alpha}=$ $K_{i, t+1} \omega_{i, t+1}^{*} \frac{\kappa}{\alpha}$.

If, on the contrary, the capital stock is insufficient - i.e. $\kappa K_{i, t+1}<Y_{i, t+1}^{*}$ - the capital stock will be used at full capacity $\left(\omega_{i, t+1}=1\right)$ but the desired scale of activity will not be reached. Desired employment in this case will be at the efficient level, i.e. $\hat{N}_{i, t+1}=$

\footnotetext{
${ }^{18}$ In fact investment and price/quantity decisions occur at the same time.
} 
$K_{i, t+1} \frac{\kappa}{\alpha}$. Desired employment therefore is determined as follows:

$$
N_{i, t+1}^{*}=\min \left(\frac{Y_{i, t+1}^{*}}{\alpha}, K_{i, t+1} \frac{\kappa}{\alpha}\right)
$$

According to eq. 5.8 desired employment is equal to the minimum between the amount of labor needed to reach the desired scale of activity and the amount of labor corresponding to an efficient use of resources given the available capital stock. Given desired employment and actual employment, i.e. $N_{i, t}$, at the beginning of period $t+1$ the firm decides vacancies to post as follows:

$$
v_{i, t+1}=\max \left(N_{i, t+1}^{*}-N_{i, t}, 0\right)
$$

A vacancy is filled only if the firm is visited by an unemployed worker. Since the nominal wage is given and uniform, the probability of filling the vacancy depends only on the number of unemployed workers visiting the firm. Thus actual employment $N_{i, t+1}$ may be smaller than desired employment $N_{i, t+1}^{*}$, the difference between the two being unfilled vacancies. On the contrary, if $N_{i, t+1}^{*}<N_{i, t}$, i.e the number of actual workers exceeds the level of desired employment, the firm selects at random $n_{i, t+1}=N_{i, t}-N_{i, t+1}^{*}$ workers and fires them.

\subsubsection{A numerical example}

Consider a simplified framework in which the past consists only of two periods (t-2 and t-1). For simplicity suppose capital was fully utilized in the past. Suppose capital in t-2 and t-1 were 95 and 105 respectively. Average capital "in the past" therefore is $\bar{K}_{i, t-1}=100$. Suppose that, absent investment, capital would depreciate by $2 \%$ per period so that after 4 periods $(t, t+1, t+2$ and $t+3)$ capital would be equal to 92 . In order to maintain the original capital the firm has to plan $I_{i, t}^{r}=8$ of capital replacement. Assuming that the desired capacity utilization rate is $\bar{\omega}=0.85$, the desired capital is $K_{i, t+1}=100 / 0.85=117.65$.

Suppose in t-1 investment was 10.4. Hence capital in t will be equal to $K_{i, t}=(1-$ $0.08) 105+10.4=107$. Therefore net capital addition in t should be $117.65-107=10,65$. 
Gross capital formation in t therefore would be $10.65+8=18.65$. Capital available in $\mathrm{t}+1$ therefore will be $K_{i, t+1}=(1-0.08) 105+18.65=115.25$. Assuming that capital is fully utilized and assuming that the productivity of capital is $1 / 3$ and the productivity of labor is $1 / 10$, production in $\mathrm{t}$ will be $105 / 3=35$ and desired employment will be $35 \times 10=350$. Suppose this is also current employment.

Consider now three scenarios. In the first one, desired production in $t+1$ is 37 . Then the stock of capital needed to produce this amount is $37 \times 3=111$. There is enough capital to reach this level of production. Therefore the firm chooses the desired rate of capacity utilization: $111 / 115.25=0.96$. The desired level of employment is $37 \times 10=370$. By assumption, the operating workforce was 350. Then the firm will post 20 vacancies. In the second scenario desired production in $t+1$ is 50 . Then the stock of capital needed to produce this amount is $50 \times 3=150$. There is not enough capital to reach this level of production. Therefore the firm utilizes all the capital, i.e. 115.25. Hence total output at the maximum will be $115.25 / 3=38.42$. The desired level of employment is $38.42 \times 10=384.2$. The workforce being 350 , vacancies will be 34.2 .

Finally, consider the scenario in which desired production in $t+1$ is 30 . Then the stock of capital needed to produce this amount is $30 \times 3=90$. There is enough capital to reach this level of production. Therefore the firm chooses the desired rate of capacity utilization: $90 / 115.25=0.78$. The desired level of employment is $30 \times 10=300$. Since the workforce is 350, the firm will fire 50 workers.

It is important to notice that the actual scale of activity will depend on the interactions on the labor market, on the K-goods market and on the credit market. Moreover it will depend on the inputs availability. In fact in the case in which the firm cannot hire the amount of labor needed to produce desired production, or cannot buy the desired amount of capital, either because of the specific market situation or because of the high price of credit, actual production will be smaller than desired production.

In order to visualize the problem of the C-firm, let us assume that the firm's desired scale of activity at time $t$ is described by the isoquant denoted with $Y_{i, t}^{*}=Y^{*}$ in figure 3 and that the capital stock is $K_{i, t}=K_{i, t}^{*}=K^{*}$ (i.e. the capital stock is fully utilized) so that efficient employment will be equal to $N_{i, t}^{*}=N^{*}$. Suppose that desired production 
in the next period is $Y_{i, t+1}^{*}=Y_{1}^{*}>Y^{*}$, hence the isoquant corresponding to desired production in $t+1$ is higher than the isoquant corresponding to desired production in $t$. Since the firm is already operating at full capacity in $t$ (producing the quantity $Y^{*}$ ), she will demand in $t$ the capital needed to reach the desired isoquant in period $t+1$. If on the contrary $Y_{i, t+1}^{*}=Y_{1}^{*}<Y^{*}$, the isoquant capturing desired production will

\section{Leontief isoquant and desired capital}

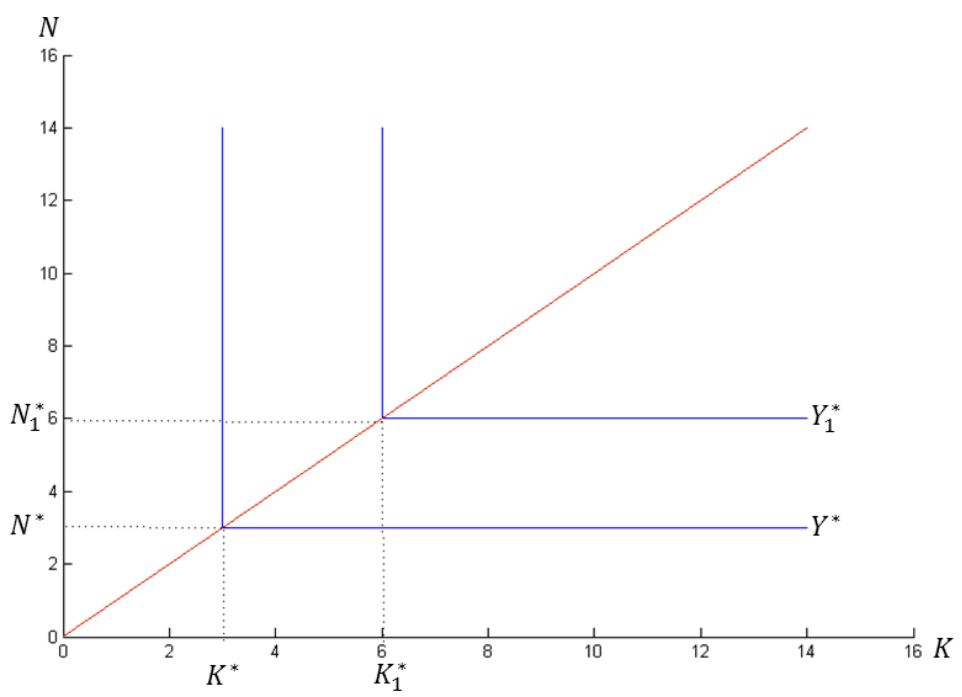

Figure 3: Firms behavior, increasing production

be below the current isoquant as shown in figure 4 , the firm will demand $N_{1}^{*}$ (i.e. the workforce needed to produce $Y_{1}^{*}$ ), hence she will under-utilize capacity and will demand zero capital. The framework described above implies full flexibility when production is scaled down, and a capacity constraint when output should be increased.

\section{K-firms}

In the K-goods market (K-market for short), C-firms are buyers of capital goods sold by K-firms. The $\mathrm{j}$-th firm in the $\mathrm{K}$-sector $\left(j=1,2, \ldots, F_{k}\right)$ produces a K-good using only labor. We assume imperfect information and the existence of transaction costs also in the K-market so that price and quantity are decided by K-firms by means of the same adaptive process described above for C-firms (see subsection 5.1). At the beginning of time $t$ the $\mathrm{j}$-th firm sets the status quo $\left(P_{j, t}, Y_{j, t}\right)$. At the end of period $t$ the firm 


\section{Leontief isoquant and desired capital}

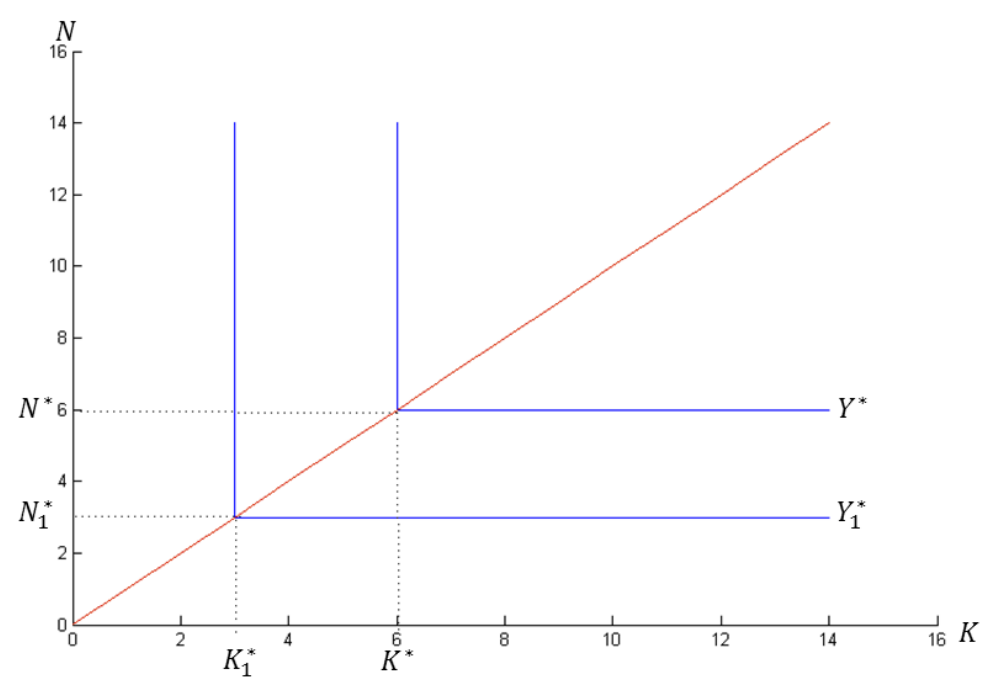

Figure 4: Firms behavior, decreasing production

learns also the average price $P_{k, t}$. Once production has been carried out and search and matching has taken place, the $\mathrm{j}$-th firm can observe actual demand $Y_{j, t}^{d}$ which can differ from current production. The difference between the two $\Delta_{i, t}=Y_{i, t}-Y_{i, t}^{d}$, if positive, measures involuntary inventories. This is a signal of excess supply i.e. of a positive forecasting error. Since capital is durable, we assume that K-goods are storable, hence the K-firm can carry inventories over from today to tomorrow and satisfy future demand. We assume, however, that inventories are subject to fast depreciation $\delta^{k}>\delta$

If production in $t$ is smaller or equal to actual demand, i.e. $\Delta_{i, t} \leq 0$ sales are equal to production but there will be a queue of unsatisfied C-firms. This is a signal of excess demand, i.e. a negative forecasting error. No inventory accumulation and no queues signal "equilibrium" (hence no forecasting error).

\subsection{K-price and quantity decision}

The firm receives two signals: the price charged by competitors and the level of inventories. On the basis of this two signals the firm forms expectations on future demand and sets desired production at the level of expected demand i.e. $\left.Y_{j, t+1}^{*}=Y_{j, t+1}^{e}\right)$. We assume 
the firm adopts the following adaptive rule in order to change the price:

$$
P_{j, t+1}= \begin{cases}P_{j, t}\left(1+\eta_{j, t+1}\right) & \text { if } \Delta_{j, t} \leq 0 \text { and } P_{j, t}<P_{k, t} \\ P_{j, t}\left(1-\eta_{j, t+1}\right) & \text { if } \Delta_{j, t}>0 \text { and } P_{j, t}>P_{k, t}\end{cases}
$$

where $\eta_{i, t+1} \in(0,0.1)$ The firm decides to update the desired scale of activity $Y_{j, t+1}^{*}$ on the basis of expectation of future demand $Y_{j, t+1}^{e}$ and the level of inventories $Y_{j, t+1}^{k}$ as follows:

$$
\left.Y_{i, t+1}^{*}=Y_{i, t+1}^{e}\right)-Y_{j, t+1}^{k}= \begin{cases}Y_{j, t}+\rho\left(-\Delta_{j, t}\right)-Y_{j, t}^{k} & \text { if } \Delta_{j, t} \leq 0 \text { and } P_{j, t}>P_{k, t} \\ Y_{i, t}-\rho \Delta_{i, t}-Y_{j, t}^{k} & \text { if } \Delta_{i, t}>0 \text { and } P_{i, t}<P_{k, t}\end{cases}
$$

\subsection{K-production, labor requirement and vacancies}

The j-th firm produces output $Y_{j, t}$ by means of a linear technology:

$$
Y_{j, t}=\alpha N_{j, t}
$$

where $\alpha$ is the productivity of labor, exogenous, constant and uniform across firms. ${ }^{19}$ Given the desired employment and the amount of labor already employed (i.e. $N_{j, t}$ ) at the beginning of period $t+1$, i.e. before the labor market opens, the firm decides vacancies to post according to :

$$
v_{j, t+1}=\max \left(N_{j, t+1}^{*}-N_{j, t}, 0\right)
$$

If $N_{i, t+1}^{*}>N_{i, t}$ the firm posts vacancies. The K-market is therefore modeled as a search and matching mechanism: each C-firm randomly selects $Z_{k} \mathrm{~K}$-firms, sorts them by selling price and demand capital goods starting from the firm charging the lowest price. K-firms with lower prices will receive on average higher demand for capital goods. As in the job market, the search and matching mechanism implies coexistence of queues of unsatisfied C-firms at some K-firms and involuntary inventories of K-goods at some other firms.

\footnotetext{
${ }^{19} \mathrm{We}$ assume that the productivity of labor is the same, i.e. $\alpha$ in both sectors.
} 


\section{$7 \quad$ The financing gap}

At time $t$, the i-th C-firm asks for a bank loan if liquid resources $D_{i, t-1}$ are in short supply with respect to the sum of the wage bill $w N_{i, t}$ and investment expenditure $P_{k, t-1} I_{i, t}$ where $P_{k, t-1}$ represents the price index of capital goods. ${ }^{20}$. In other words, the C-firm asks for a bank loan only if there is a financing gap defined as follows:

$$
F_{i, t}=\max \left(w N_{i, t}+P P_{k, t-1} I_{i, t}-D_{i, t-1}, 0\right)
$$

In $t$ also K-firms demand loans if they have a financing gap. The j-th K-firm's financing gap, i.e. $F_{j, t}$, is defined as follows:

$$
F_{j, t}=\max \left(w N_{j, t}-D_{j, t-1}, 0\right)
$$

Notice that the K-firm needs to finance only the "working capital" i.e. the wage bill.

\section{The Bank}

For the sake of simplicity we assume that there is only one commercial bank. Households, capitalists and firms hold deposits at the bank to manage their liquidity. The bank accepts deposits in unlimited amount at zero interest rate. On the other hand, firms demand credit according to their production plans and the resulting financing gaps. The bank has to decide both the price (interest rate) and the quantity of loans to be supplied to each firm on the basis of her assessment of the firm's financial fragility proxied by leverage. We assume that the bank has full access to the firm's balance sheet so that she can compute the following leverage ratio $\lambda_{f, t}, \mathrm{f}=1,2 \ldots \mathrm{F}$ :

$$
\lambda_{f, t}=\frac{L_{f, t-1}+F_{f, t}}{E_{f, t-1}+L_{f, t-1}+F_{f, t}}
$$

${ }^{20}$ Since the C-firm in $t$ does not have sufficient information about the simultaneous decisions taken by $\mathrm{K}$-firms (such as the price of K-goods), in order to evaluate the financing gap they use the price index of $\mathrm{K}$-goods in the previous period 

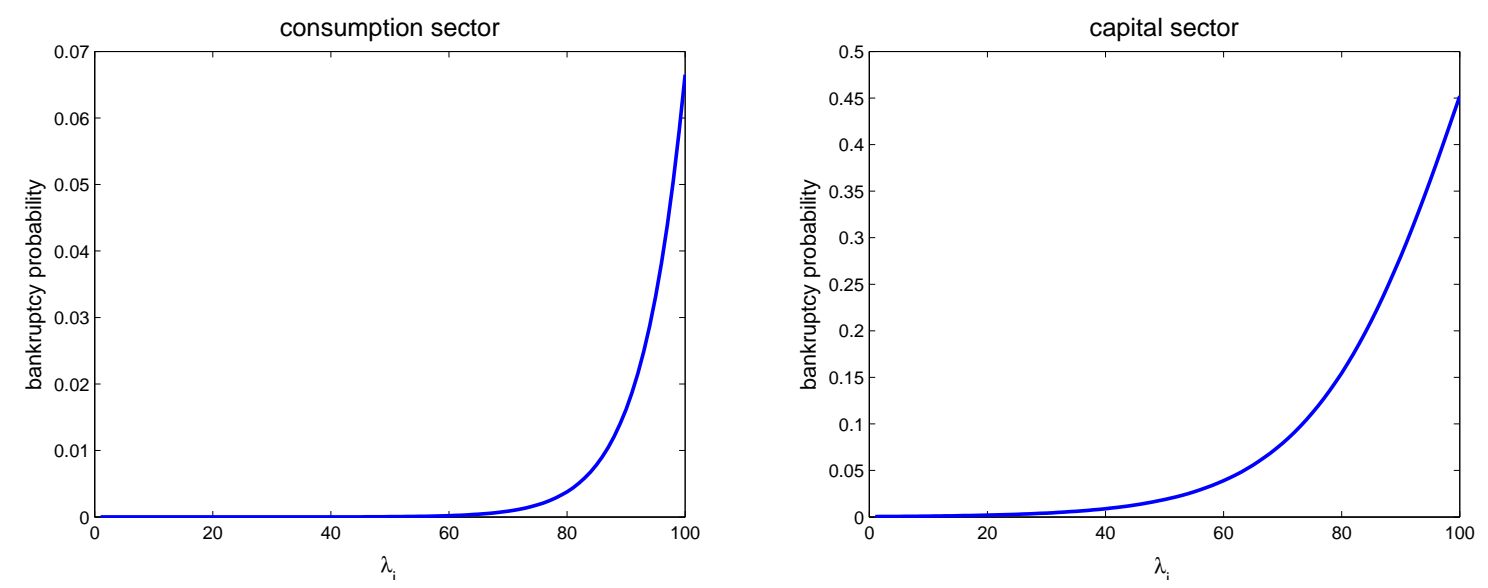

Figure 5: Typical estimated bankruptcy probability as a function of leverage. Left: estimated bankruptcy probability for the consumption sector. Right: estimated bankruptcy probability for the capital sector.

where $L_{f, t-1}$ and $E_{f, t-1}$ are the end-of-period values of debt and equity respectively in $t-1$ (by construction, this sum coincides with the total nominal value of assets) and $F_{f, t}$ represents the current financing gap (i.e. the demand for a new loan). Notice that $0 \leq \lambda_{f, t}<1$. If $\lambda_{f, t}=0$ the firm is self-financed (maximum financial robustness): total assets will be equal to net worth (in t-1). On the contrary when $\lambda_{f, t} \rightarrow 1$, equity tends to zero (maximum fiinancial fragility): total assets will be equal to total loans. ${ }^{21}$

We assume that the bank has full access to past individual data on the financial fragility (measured by leverage) and the state (surviving or bankrupt) of each firm she has extended a loan to over a certain time span $\hat{T}$. Using these data, the bank will populate two datasets for C-firms and K-firms respectively. Using the dataset for C-firms the bank will estimate a logistic regression between the bankruptcy probability $\phi_{c}$ and the individual leverage $\lambda_{c}$ for C-firms: $\phi_{c}=f^{c}\left(\lambda_{c}\right)$. Following the same procedure and using the dataset for K-firms, the bank will also estimate the logistic relationship between the bankruptcy probability $\phi_{k}$ and the individual leverage $\lambda_{k}$ for K-firms: $\phi_{k}=f^{k}\left(\lambda_{k}\right){ }^{22}$ In

\footnotetext{
${ }^{21}$ The definition of leverage we adopt here for convenience is a monotonic increasing transformation of the usual definition according to which leverage is the ratio of assets to equity: $\hat{\lambda}_{f, t}=\left(L_{f, t-1}+\right.$ $\left.E_{f, t-1}+F_{f, t}\right) / E_{f, t-1}$. Our measure of leverage has the advantage of ranging between zero and one.

${ }^{22}$ We assume that, in the estimation of the default probability, the bank will make use only of the last $\hat{T}$ periods. Each period the logistic relationship will be re-estimated discarding the oldest observation and incorporating the newest one (and therefore maintaining the length of the time window and the size of the dataset unaltered. The reason for building up two different datasets is that the structural features of C-firms and K-firms are indeed quite different. Since a minimum number of data points, i.e. bankruptcies, is necessary to obtain a good fit and since the number of C-firms is 4 times the number of K-firms in the simulations, also the time span $\hat{T}$ ) used in the estimation will be different for the two sectors.
} 
figure 5 we show an example of an estimated default probability function for the C-sector and the K-sector respectively. Notice that, in both cases, for values of $\lambda$ tending to 1 the estimated probability of bankruptcy tends to a level well below 1 (around 0.1 in the C-sector and around 0.5 in the K-sector). The grim reality is that when $\lambda$ tends to 1 the firm is indeed on the verge of bankruptcy (because equity is going to be depleted soon) but this risk is statistically underestimated by the logistic regression the bank uses to assess the riskiness of the firm.

\subsection{Interest rates}

We assume that the loan repayment schedule is the same for all the firms and is defined as follows. Suppose the firm receives a loan of 1 dollar in period $t$. We assume that in each subsequent period the firm will pay back a share $\theta$ of the loan outstanding (i.e. carried out from the previous period) and the agreed interest rate $r$ (per period). ${ }^{23}$ Let us define a risk free firm as a firm that survives (does not go bankrupt) for an infinite number of periods. The total payment due by the risk free firm is:

$$
R=\sum_{t=0}^{\infty}(\theta+r)(1-\theta)^{t}
$$

Expanding the geometric series, we get:

$$
R=\left(1+\frac{r}{\theta}\right)
$$

where $\mathrm{R}$ is the gross rate of return on lending to a risk free firm, $r / \theta$ is the net rate of return and $r$ is the risk free rate, that we assume to be given. The risk free rate is the natural candidate to play the role of the policy rate (the instrument of monetary policy) in our framework.

\footnotetext{
${ }^{23}$ Ignoring interest payments, if the firm paid $\theta$ per period the loan of 1 dollar would be extinguished in $1 / \theta$ periods, i.e. $1 / \theta$ would be the maturity of the loan. In the repayment schedule we consider, the agent pays $\theta$ in the first period, $\theta(1-\theta)$ in the second period and so on. This means that the loan will be completely reimbursed asymptotically on an infinite time horizon. The implicit maturity is $1 / \theta$ but the borrower is entitled to estinguish the debt over an infinite horizon. By way of example, suppose $\theta=0.05$ i.e. the firm pays back $5 \%$ of the existing debt per period. The implicit maturity is 20 years. After twenty years, however, according to the repayment schedule here considered the firm has repaid approximately $2 / 3$ of the loan.
} 
Consider first C-firms. The bank will charge the i-th C-firm an interest rate equal to the risk free rate augmented by a mark up which takes into account the firm's riskiness evaluated by means of the estimated probability of bankruptcy. The bank will retrieve the probability of bankruptcy of the i-th firm from the logistic regression above: $\phi_{i, t}=$ $f^{c}\left(\lambda_{i, t}\right)$. The expected number of periods that a firm will survive (i.e. the time to default) is the reciprocal of the bankruptcy probability: ${ }^{24}$

$$
T_{i, t}=\frac{1}{\phi_{i, t}}=\frac{1}{f^{c}\left(\lambda_{i, t}\right)}
$$

The payment due by a firm with bankruptcy probability $\phi_{i, t}$ on a loan of 1 dollar - i.e. the gross rate of return on lending to a the risky i-th firms - is equal to:

$$
R_{i, t}=\sum_{t=0}^{T_{i, t}}\left(\theta+r_{i, t}\right)(1-\theta)^{t}
$$

from which expanding the geometric series we get:

$$
R_{i, t}=\left(\theta+r_{i, t}\right) \frac{1-(1-\theta)^{T_{i, t}+1}}{\theta}
$$

From the relation above it is clear that the return on lending to a risky $\mathrm{C}$-firm depends on the expected survival time $T_{i, t}$, which depends on the estimated bankruptcy probability and in the end on the firm's leverage.

The same type of relationship applies also to K-firms. The return on lending to the risky j-th K-firm is:

$$
R_{j, t}=\left(\theta+r_{j, t}\right) \frac{1-(1-\theta)^{T_{j, t}+1}}{\theta}
$$

where

$$
T_{j, t}=\frac{1}{\phi_{j, t}}=\frac{1}{f^{k}\left(\lambda_{j, t}\right)}
$$

\footnotetext{
${ }^{24}$ Alternatively, one can think of the probability of default as the reciprocal of the the time to default.
} 
For simplicity, we assume that the bank is risk neutral. The bank will lend to any firm inasmuch as the return on lending to that firm is not smaller than the return on an alternative risk free asset (which measures the opportunity cost of lending). We assume that this required risk free return is a multiple of the return on lending to a risk free firm $R \mu$ where $\mu>1$. Once all the arbitrage opportunities have been exploited, the following equality will hold true for the generic f-th firm: $R_{f, t}=R \mu$. Using 8.3 and 8.6 and denoting $\frac{1-(1-\theta)^{T_{i, t}+1}}{\theta} \equiv \Xi\left(T_{i, t}\right)$ for expositional simplicity, from the no-arbitrage condition above we obtain the interest rate charged by the bank to the i-th C-firm:

$$
r_{i, t}=\mu\left[\frac{1+\frac{r}{\theta}}{\Xi\left(T_{i, t}\right)}-\theta\right]
$$

It turns out that the interest rate charged by the bank to the i-th firm is a mark up over the expression in brackets, which in turn is increasing with the risk free rate, decreasing with the implicit maturity and increasing with the firm's leverage (which affects the time to default).

Using 8.3 and 8.7 and denoting $\frac{1-(1-\theta)^{T_{j, t}+1}}{\theta} \equiv \Xi\left(T_{j, t}\right)$ from the no-arbitrage condition we obtain the interest rate charged by the bank to the $\mathrm{j}$-th K-firm (the interpretation is straightforward):

$$
r_{j, t}=\mu\left[\frac{1+\frac{r}{\theta}}{\Xi\left(T_{j, t}\right)}-\theta\right]
$$

An increase of the risk free rate raises the financial costs for the firm (cost channel in the transmission of monetary policy shock). If the firm is already quite fragile this interest rate policy will push the firm even closer to bankruptcy. In turn, if the firm goes bankrupt, the whole stock of credit is lost, hence the equity of the bank will decrease (see below).

\subsection{Supply of loans}

We assume that the bank's risk manager aims at limiting the maximum loss deriving from commercial loans. For each loan, we assume the maximum admissible loss is $\zeta E_{t}^{b}$ 
where $0<\zeta<1$, and $E_{t}^{b}$ represents the equity of the bank in period $t$. The expected loss from lending to the $\mathrm{f}$-th firm, on the other hand, is $\phi_{f}\left(\Delta L_{f, t}+L_{f, t-1}\right)$ where $\phi_{f}$ is the bank's estimated probability of bankruptcy for firm $f$ and $\Delta L_{f, t}=L_{f, t}-L_{f, t-1}$ is the new loan extended by the bank to the firm. Hence the following inequality must hold:

$$
\phi_{f}\left(\Delta L_{f, t}+L_{f, t-1}\right) \leq \zeta E_{t}^{b}
$$

Since $L_{f, t-1}$ is known, the only decision variable for the bank is the amount of loans she extends to the f-th firm, i.e $\Delta L_{f, t}$ :

$$
\Delta L_{f, t} \leq \frac{\zeta E_{t}^{b}-\phi_{f} L_{f, t-1}}{\phi_{f}} \equiv \bar{F}_{f, t}
$$

where $\bar{F}_{f, t}$ is the maximum size of the new loan the bank is willing to supply to firm $f$, given the estimated probability of default. ${ }^{25}$ If the loan demanded by the firm (i.e. the financing gap $F_{f, t}$ ) is smaller than the maximum loan the bank is willing to extend (i.e. $\left.\bar{F}_{f, t}\right)$, then the bank will accommodate the demand for credit: $\Delta L_{f, t}=F_{f, t}$; if, on the contrary, the financing gap $\left.F_{f, t}\right)$ is greater than the maximum loan the bank is willing to extend, the bank will ration credit to the borrower: $\Delta L_{f, t}=\bar{F}_{f, t}$. In symbols:

$$
\Delta L_{f, t}=\min \left(F_{f, t}, \bar{F}_{f, t}\right)
$$

From the inequality above, given the definition of financing gap and 8.12 we can infer that an increase of the net worth of the bank and/or of the borrowing firm - so that the firms leverage and the estimated probability of bankruptcy go down - relaxes the constraint represented by the maximum admissible loan supply and makes credit rationing less likely.

Although being very simple the bank's risk management is effective because it prevents the bank from taking too large a risk on the loan market.

For the sake of simplicity we assume that firms' owners own the bank as well, in particular

\footnotetext{
${ }^{25}$ The inequality 8.12 may be expressed also in terms of stocks: $L_{f, t} \leq \frac{\zeta E_{t}^{b}}{\phi_{f}} \equiv \bar{L}_{f, t}$ where $\bar{L}_{f, t}$ is the maximum amount of loans (total outstanding debt of the firm) the bank is willing to supply to firm $f$.
} 
each one holds the same number of shares. At the end of each period, if net profits are positive, the bank will distribute dividends. Retained profits, on the other hand, will be added to her equity.

\subsection{Accounting}

In this section we will describe the accounting framework of the model, focusing on the system of interrelated balance sheets. We will also show the changes in liquidity generated by the financial structure of the balance sheets. As far as households (workers and capitalists) are concerned, the situation is simple. The h-th worker has (non-negative) wealth $E_{h, t}$ which coincides with deposits $D_{h, t}: E_{h, t}=D_{h, t}, \mathrm{~h}=1,2 \ldots, \mathrm{H}$. The same assumption applies to capitalists: $E_{f, t}=D_{f, t}, \mathrm{f}=1,2 \ldots, \mathrm{F} .{ }^{26}$ Hence, savings are deposited at the bank:

$$
D_{h, t}=D_{h, t-1}+Y_{h, t}-C_{h, t}
$$

Consider now the balance sheet of the generic C-firm. The balance sheet accounting identity is:

$$
v_{i, t}^{k} K_{i, t}+D_{i, t}=L_{i, t}+E_{i, t}
$$

where $v_{i, t}^{k}$ is the book value of physical capital $K_{i, t}, D_{i, t}$ is the firm's liquidity (deposits at the bank), $L_{i, t}$ is the outstanding debt and $E_{i, t}$ is net worth.

From this identity it is easy to infer that liquidity is updated as follows:

$$
D_{i, t}=D_{i, t-1}+\Pi_{i, t}+\Delta L_{i, t}-\theta L_{i, t}-P_{k, t} I_{i, t}
$$

where $\Pi_{i, t}$ are the firm's profits, $\theta L_{i, t}$ is debt installment and $P_{k, t} I_{i, t}$ are expenditures in new capital goods evaluated at the current price of capital goods $P_{k, t}$ At the end of

\footnotetext{
${ }^{26}$ By assumption, households do not run into debt.
} 
period $t$ the profits of the i-th C-firm will be:

$$
\Pi_{i, t}=P_{i, t} Q_{i, t}-\left(w N_{i, t}+v_{i, t}^{k} I_{i, t}^{r}\right)-\hat{r}_{i, t} L_{i, t}-D i v_{i, t}
$$

where $Q_{i, t}=\min \left(Y_{i, t}, Y_{i, t}^{d}\right)$ is the amount of consumption goods actually sold, ${ }^{27} w N_{i, t}$ is the wage bill, $v_{i, t}^{k} I_{i, t}^{r}$ represents the cost of capital due to the replacement of worn out equipment $I_{i, t}^{r}$ evaluated at the book value $v_{i, t}^{k}, \hat{r}_{i, t} L_{i, t}$ are interest payments on the stock of debt, Div $v_{i, t}$ are dividends.

In order to understand the definition of interest payments, let us remind the reader that the bank extends loans to the same firm at different interest rates in different time periods - essentially because the firm's financial fragility may change over time, see 8.9. We define $\hat{r}_{i, t}$ as the average cost of outstanding debt, which is updated according to the following rule:

$$
\hat{r}_{i, t}=\frac{\hat{r}_{i, t-1} L_{i, t-1}+r_{i, t} \Delta L_{i, t}}{L_{i, t-1}+\Delta L_{i, t}}
$$

It is easy to see that the equation above can be written as follows:

$$
\hat{r}_{i, t}=\hat{r}_{i, t-1}\left(1-x_{i, t}\right)+r_{i, t}\left(x_{i, t}\right)
$$

where $x_{i, t}=\Delta L_{i t} / L_{i t}$. By repeated substitution, it is easy to see that the current cost of debt turns out to be a weighted average of past interest rates with time-varying weights:

$$
\hat{r}_{i, t}=r_{i, t} x_{i, t}+r_{i, t-1} x_{i, t-1}\left(1-x_{i, t}\right)+r_{i, t-2} x_{i, t-2}\left(1-x_{i, t-1}\right)+\ldots
$$

If equity turns negative, the firm goes bankrupt. Bankruptcy implies that debt and liquidity are absorbed by the bank and a new firm will enter the market (one to one replacement) with equity determined by the wealth of the owner of the bankrupt firm ${ }^{28}$.

\footnotetext{
${ }^{27}$ The product $P_{i, t} Q_{i, t}$ represents sale revenues. If the firm has ended up with positive inventories, i.e. $\Delta_{i, t}>0$, then $Q_{i, t}=Y_{i, t}-\Delta_{i, t}=Y_{i, t}^{d}$. If, on the other hand, there is a queue of unsatisfied consumers, i.e. $\Delta_{i, t}<0$, then $Q_{i, t}=Y_{i, t}$.

${ }^{28}$ Since there is no secondary market for capital goods we assume that the capital stock owned by the bankrupt firm is left to the firm replacing it.
} 
Let's turn now to K-firms. The balance sheet identity of the generic K-firm is

$$
D_{j, t}=E_{j, t}+L_{j, t}
$$

where the meaning of the symbols is straightforward. From this identity it is easy to infer that liquidity is updated as follows:

$$
D_{j, t}=D_{j, t-1}+\Pi_{j, t}+\Delta L_{j, t}-\theta L_{j, t}
$$

At the end of period $t$ the profits of the j-th K-firm will be:

$$
\Pi_{j, t}=P_{j, t} Q_{j, t}-w N_{j, t}-\hat{r}_{j, t} L_{j, t}-D i v_{j, t}
$$

where $Q_{j, t}=\min \left(Y_{j, t}, Y_{j, t}^{d}\right)$ is the amount of capital goods actually sold, ${ }^{29}$ Moreover

$$
\hat{r}_{j, t}=\hat{r}_{j, t-1}\left(1-x_{j, t}\right)+r_{j, t}\left(x_{j, t}\right)
$$

where $x_{j, t}=\Delta L_{j, t} / L_{j, t}$. If the $\mathrm{j}$-th firm's equity turns negative, the firm goes bankrupt and will be replaced by a new firm with equity determined by the wealth of the owner of the bankrupt firm.

Let's turn now to the bank. The balance sheet accounting identity is:

$$
R_{t}^{b}+L_{t}=D_{t}+E_{t}^{b}
$$

where $R_{t}^{b}$ are the bank's reserves (bank's deposits at the central bank), $L_{t}$ are total loans, $D_{t}$ are total deposits and $E_{t}^{b}$ is the bank's net worth.

At the end of period $t$ the profits of the bank will be:

$$
\Pi_{t}^{b}=\sum_{s=1}^{F_{s}} r_{s, t} L_{s, t}
$$

\footnotetext{
${ }^{29}$ The same remarks on the relationship between sales, demand, supply and inventories that apply to the generic C-firm also apply to the generic K-firm, with the obvious caveat that capital goods are durable and therefore they will be stored and depreciate gradually.
} 
Since deposits are not remunerated, the bank does not incur costs. Therefore profits coincide with revenues, which in turn coincide with interest payments from solvent borrowers (the set of solvent borrowers consists of $F_{s}$ elements).

Net worth will be updated as follows:

$$
E_{t}^{b}=E_{t-1}^{b}+\Pi_{t}^{b}-\sum_{n=1}^{F_{n}} r_{n, t} L_{n, t}
$$

The total value of interest payments due by insolvent borrowers (the set of insolvent borrowers consists of $F_{n}$ elements) is bad debt and is recorded as a negative item in the determination of current bank's equity. The system of interrelated aggregate balance sheets is represented by the following table:

\begin{tabular}{|l|l|l|l|l|l|l|}
\hline & Households & C-firms & K-firms & Bank & Central bank & Total \\
\hline Capital & & $K$ & & & & $K$ \\
Inventories & & $\Delta^{C}$ & $\Delta^{K}$ & & & $\Delta$ \\
Deposits & $D^{H}$ & $D_{C}$ & $D_{K}$ & $-D$ & & 0 \\
Reserves & & & & $R^{b}$ & $-R^{b}$ & 0 \\
Loans & & $-L_{C}$ & $-L_{K}$ & $L$ & & 0 \\
Gov. Bonds & & & & & $B$ & $B$ \\
Equity & $-E^{H}$ & $-E^{C}$ & $-E^{K}$ & $-E^{B}$ & & $-(K+\Delta+B)$ \\
\hline
\end{tabular}

Table 1: Interrelated balance sheets. Legenda: $K=$ physical capital evaluated at book value; $\Delta^{C}=$ inventories of C-goods; $\Delta^{K}=$ inventories of K-goods; $D^{H}=$ households' deposits (workers and capitalists); $D^{C}=$ deposits of C-firms; $D^{K}=$ deposits of K-firms; $D=$ total deposits $\left(D=D^{H}+D^{C}+D^{K}\right) ; R^{b}=$ bank's reserves; $L_{C}=$ loans to C-firms; $L_{C}=$ loans to K-firms; $L=$ total loans $\left(L=L^{C}+L^{K}\right) ; B=$ Government bonds (assets of the central bank); $E^{H}=$ households' wealth; $E^{C}=$ equity of C-firms; $E^{K}=$ equity of K-firms; $E^{B}=$ equity of the bank.

\section{Simulations}

In this section we will analyze the results of the simulations. The following table reports the numerical values of the parameters used in the simulation and the initial conditions. The most important feature of the model is the interaction of four types of agents (households, K-firms, C-firms and the bank) who follow adaptive behavioral rules. The interaction occurs both within the groups - through market competition - and between groups through demand-supply relationships. Interactions and bounded rationality de- 


\begin{tabular}{|c|c|c|}
\hline Parameter & Description & Value \\
\hline$T$ & Number of periods & 3000 \\
\hline$H$ & Number of workers & 3000 \\
\hline$F_{c}$ & Number of C-firms & 200 \\
\hline$F_{k}$ & Number of K-firms & 50 \\
\hline$Z_{e}$ & Number of firms visited by an unemployed worker & 5 \\
\hline$Z_{c}$ & Number of C-firms visited by a consumer & 2 \\
\hline$Z_{k}$ & Number of K-firms visited by a C-firm & 2 \\
\hline$\xi$ & Memory parameter (human wealth) & 0.96 \\
\hline$\tau$ & Dividend payout ratio & 0.2 \\
\hline$\chi$ & Fraction of wealth devoted to consumption & 0.05 \\
\hline$r$ & Risk free interest rate & 0.01 \\
\hline$\rho$ & Quantity adjustment parameter & 0.9 \\
\hline$\eta$ & Price adjustment parameter (random variable) & $\mathrm{U}(0,0.1)$ \\
\hline$\mu$ & Bank's gross mark-up & 1.2 \\
\hline$\alpha$ & Productivity of labor & 0.5 \\
\hline$\kappa$ & Productivity of capital & $1 / 3$ \\
\hline$\gamma$ & Probability of investing & 0.25 \\
\hline$\zeta$ & bank's loss parameter & 0.002 \\
\hline$\theta$ & Installment on Debt & 0.05 \\
\hline$\delta$ & Depreciation of capital & 0.02 \\
\hline$\nu$ & Memory parameter (investment) & 0.5 \\
\hline $\bar{\omega}$ & Desired capacity utilization rate & 0.85 \\
\hline$w$ & wage & 1 \\
\hline$D_{1}^{f}$ & Initial liquidity of (all) the firms & 10 \\
\hline$K_{1}$ & Initial capital & 10 \\
\hline$Y_{1}^{c}$ & Initial production (C-firms) & 5 \\
\hline$Y_{1}^{k}$ & Initial production (K-firms) & 3 \\
\hline$E_{1}^{b}$ & Initial equity of the bank & 3000 \\
\hline$E_{1}^{h}$ & Initial households' personal assets & 2 \\
\hline
\end{tabular}

Table 2: Parameters and initial conditions 
termine both the micro and the macro behavior of the economic system. In particular, without any aggregate shock, we observe noisy and autocorrelated aggregate time series and the emergence of periodic, albeit infrequent, long slumps followed by dramatic recoveries. For lack of a better term, we will label such an eventful macroeconomic episode a crisis.

In section 9.1 we are going to compare the properties of the artificial time series with the properties of the observed time series. In section 9.2 we describe and analyze one particular run as a case study to explain the emergence of a crisis in the model. It is usually very difficult to understand the causal relations in agent-based models. The richness of the model allows to reproduce interesting stylized facts but hides the mechanisms that produce such stylized facts. In section 9.3 we try and address this issue by simulating some modified versions of the model in order to provide evidence about the basic ingredients that characterize the aggregate emergent behavior of the model.

\subsection{Artificial vs observed time series.}

It is interesting to compare, at least from a qualitative point of view, the properties of the artificial and observed time series ${ }^{30}$. The artificial time series have been produced by running the model 20 times for 3000 periods and discarding the first 1000 periods to avoid any transient behavior. Both artificial and observed time series have been filtered using the HP-filter. The cycle component have been used to produce the results in table 3 and table 4 . The properties of the artificial time series are broadly comparable

\begin{tabular}{|l|l|l|}
\hline Observed Time series & Standard Deviation & First Lag Autocorrelation \\
\hline GDP & 1.6613 & 0.8485 \\
Investment & 7.5422 & 0.7952 \\
Consumption & 1.2854 & 0.8176 \\
Unemployment & 13.6804 & 0.6454 \\
\hline
\end{tabular}

Table 3: Standard deviation and first lag autocorrelation of the cycle component in the observed time series. The data have been downloaded from FRED, the codes from the first row to the last are: GDPC1, GPDIC96, PCECC9, LRUN64TTUSQ156N. All data are in real terms.

\footnotetext{
${ }^{30}$ The observed time series are taken from FRED, they are quarterly data ranging from 1955-01-01 to 2013-10-01 for unemployment (not seasonally adjusted FRED code LRUN64TTUSQ156N) and ranging from 1947-01-01 to 2013-10-01 for investments, consumption and GDP (FRED codes respectively PCECC96, GPDIC96,GDPC1).
} 


\begin{tabular}{|l|l|l|}
\hline Simulated Time series & Standard Deviation & First Lag Autocorrelation \\
\hline GDP & 1.4369 & 0.6831 \\
Investment & 15.2645 & 0.5547 \\
Consumption & 1.1784 & 0.6778 \\
Unemployment & 17.3468 & 0.6530 \\
\hline
\end{tabular}

Table 4: Standard deviation and first lag autocorrelation of the cycle component in the simulated time series. Both standard deviation and first order autocorrelation are the averages over 20 runs. The model was run for 3000 periods, only the last 2000 periods were used to compute the statistics.

to the properties of the observed time series. The volatility of consumption is lower than the volatility of GDP, which in turn is lower than the volatility of investment and of unemployment. It is interesting to note that the first lag autocorrelation of all time series is positive and high. This important feature - which characterizes also the observed time series - emerges from the interaction of the micro behaviors and does not require the presence of an aggregate shock. In section 9.3 we will show that both the adaptive behavior of the individual agents and the upstream-downstream interaction among firms in the model are crucial in generating the positive autocorrelation. Figure 6 shows the autocorrelations in artificil and observed time series up to 20 lags. The autocorrelation functions looks remarkably similar especially in the first lags. In figure 7 we show the correlation between the detrended GDP and a set of detrended aggregate variable. The figures should be read as follows. On the y-axis we show the correlation between the cycle component of the GDP at time $t$ and the cycle component of the other time series at time $t$-lag. On the $\mathrm{x}$-axis we show the lags. The peak of the absolute value of the correlation indicates whether a given variable is mostly correlated with previous GDP, future GDP or contemporaneous GDP. In figure 7 it is interesting to note that all series are coincident indicators of GDP. Moreover the off-peak behavior is similar between observed and artificial time series. The high correlation between the time series is due to the feedbacks between macro and micro level of the model. The adaptive behavior is playing again an important role in shaping the behavior of the aggregate system. 
autocorrelations in artificial time series
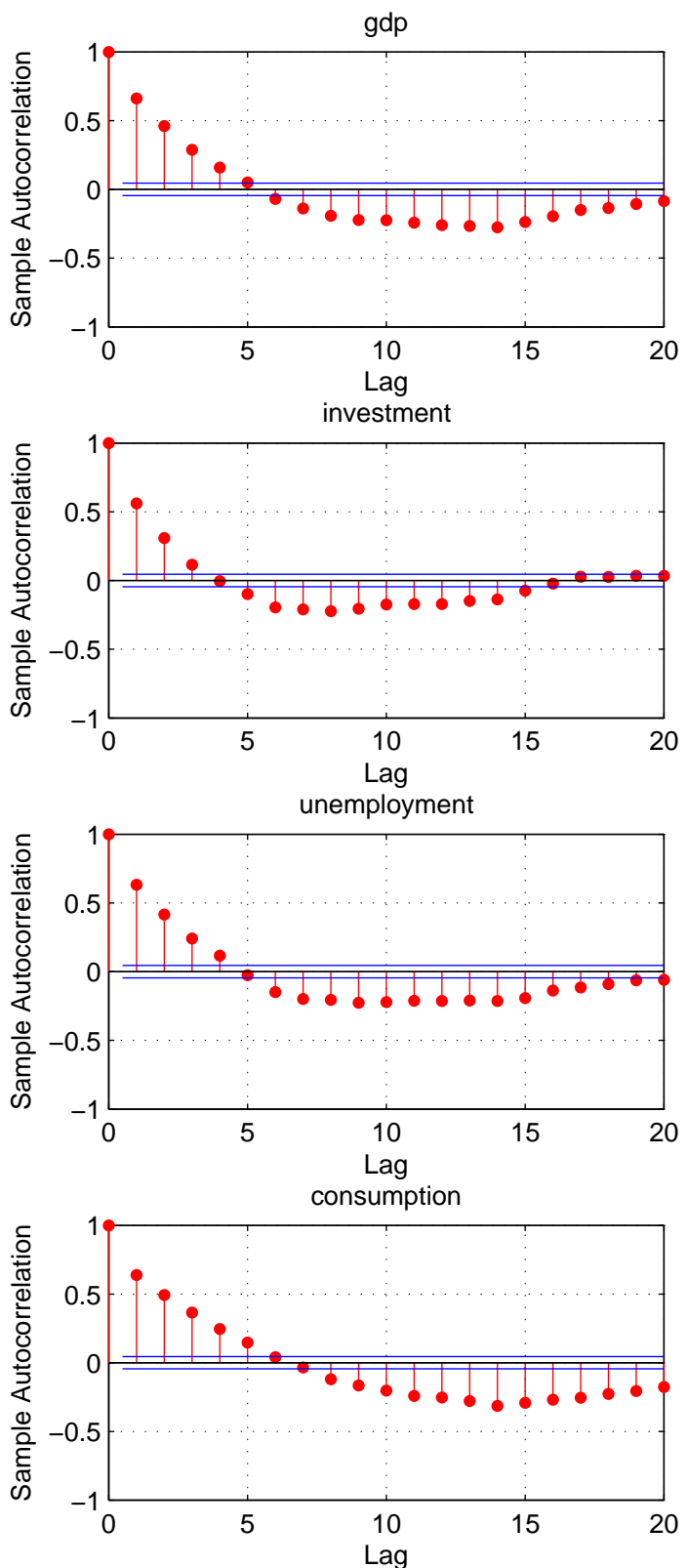

autocorrelation in observed time series
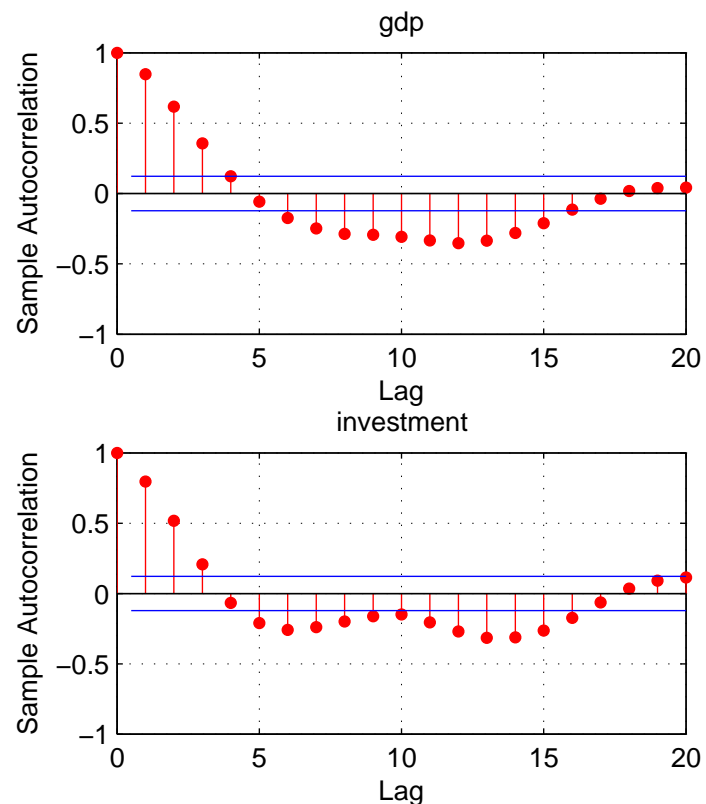

unemployment

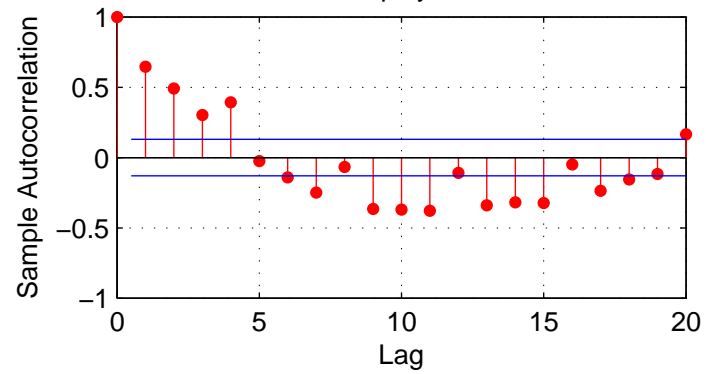

consumption

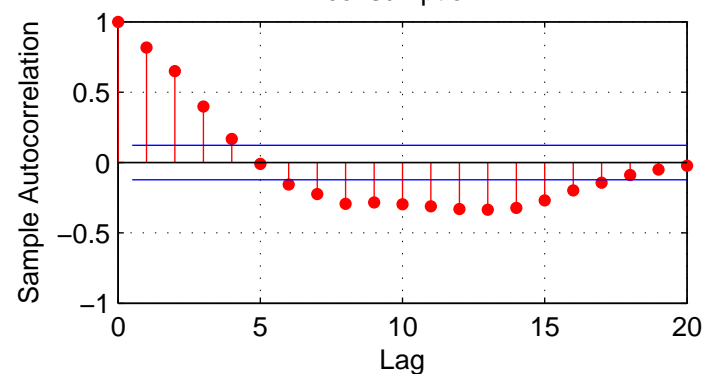

Figure 6: Unemployment, Investment, consumption and gdp lagged, correlation with gdp in observed time series 
Lagged correlations in artificial time series
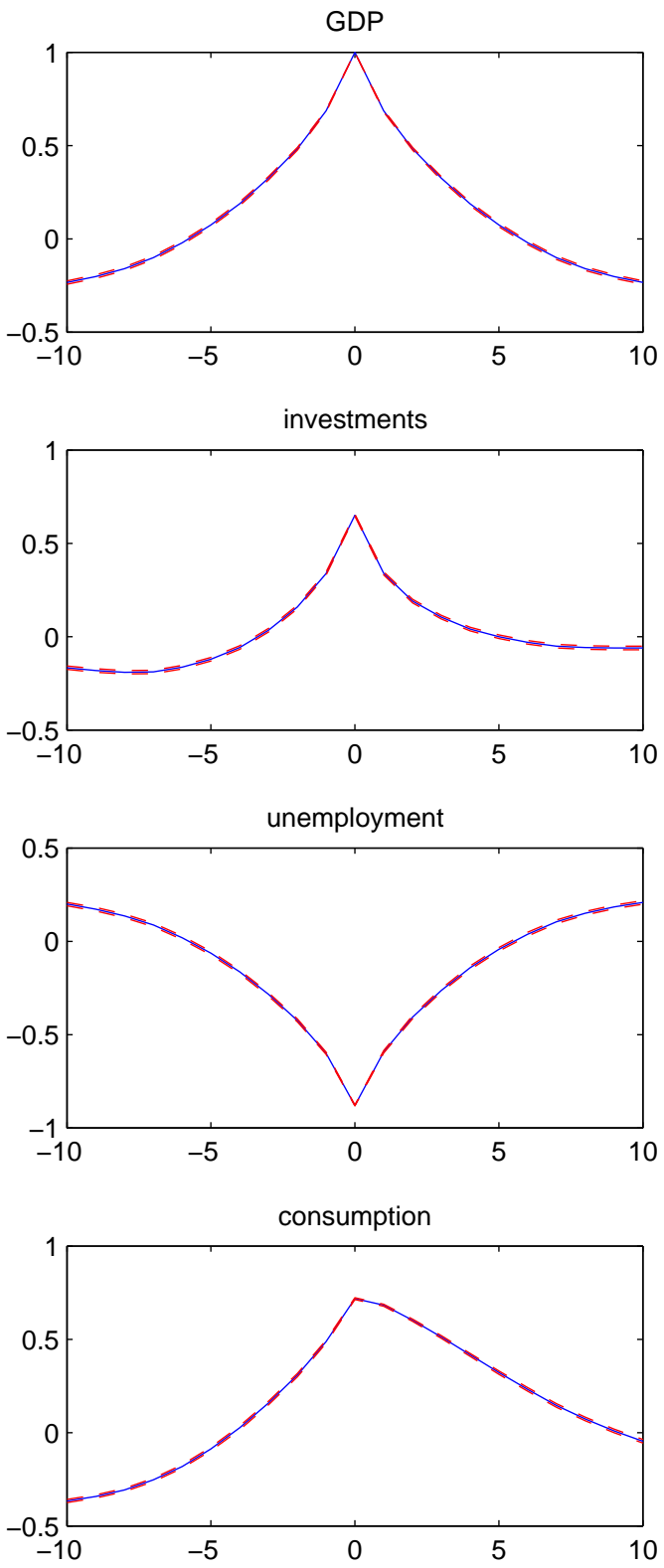

Lagged correlations in observed time series
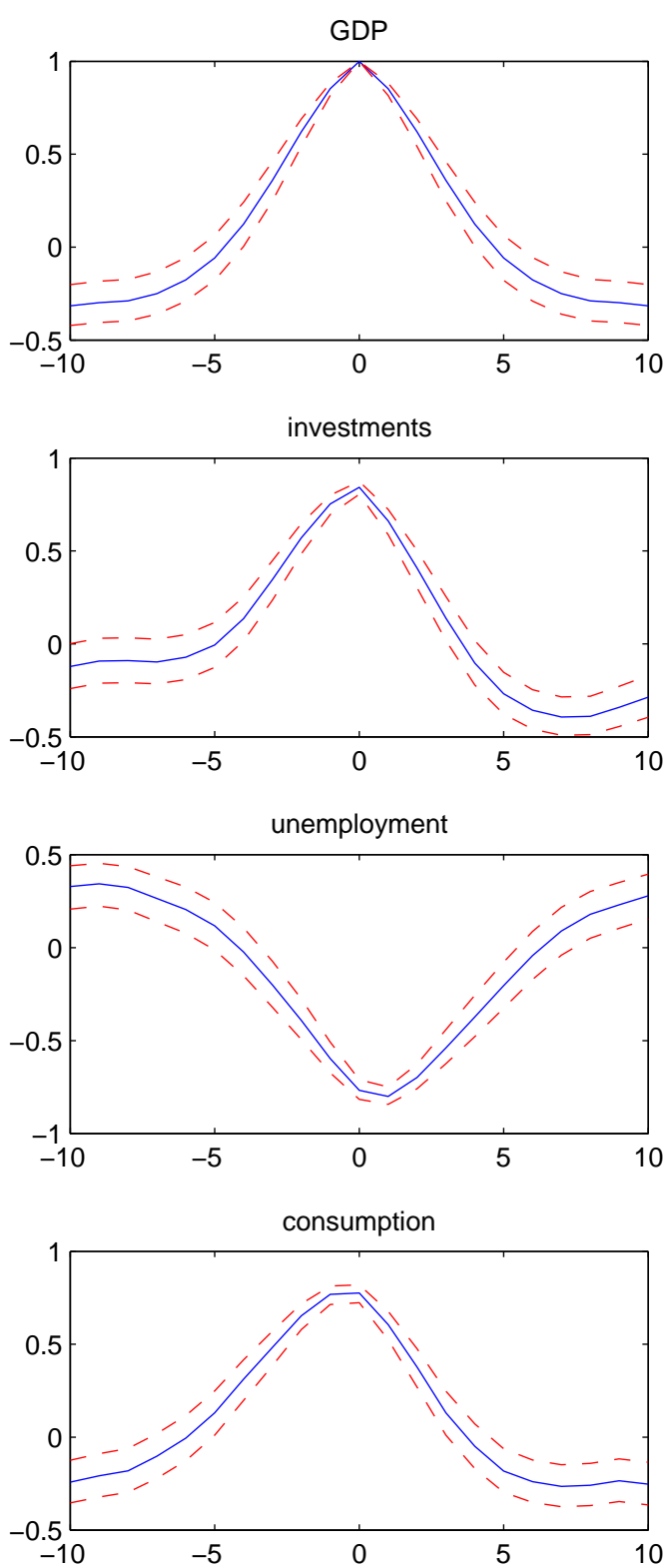

Figure 7: The time series are filtered using the hp-filter and the cycle component is considered. The figure shows the correlation between the cycle component of unemployment, investment, consumption and GDP in $t-l a g$, and the cycle component of the GDP in time $t$. 


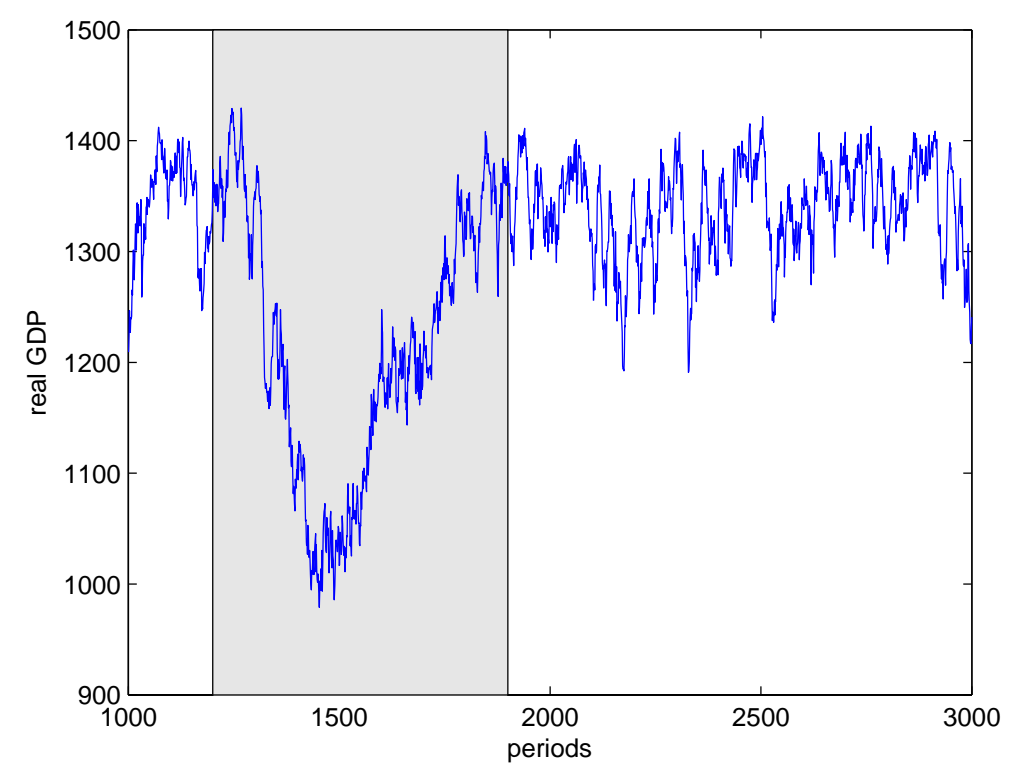

Figure 8: Real GDP in a sample simulation. The shaded area highlights a crisis period.

\subsection{The story of a crisis}

How does a crisis emerge? The question is important to understand the dynamics underlying the results of the model. The individuals and the groups/sectors (households, C-firms, K-firms and the bank) in the model are exchanging money for goods. In the stock-flow consistent close economic system reproduced by our model, aggregate "stability" - low and stable volatility of the macroeconomic time series - is associated to relatively modest changes in the composition of the money flow. Due to the absence of a coordinating mechanism between agents and between sectors, the dynamic process of exchange of money can create an accumulation of liquid resources in one of the sectors and a dramatic drain in another sector. If the change in the sectoral composition of liquid resources is strong enough a crisis - i.e. a long slump followed by a dramatic recovery - emerges. Figure 8 shows the real GDP of a sample run of the model. The GDP is fluctuating with small downturns and recoveries. The shaded area highlights an episode of crisis. The aim of this section is to understand why that particular downturn of the economic activity is so persistent, and why the crisis emerged.

The stock of monetary base or outside money (in the absence of currency, high powered money coincides with the bank's reserves) in the model is constant over time. The actual amount of money (consisting also of inside money) flowing around is endogenous 
due to credit, but the sum of the liquidity owned by the consumption firms (net of the loans) the sum of liquidity of the capital firms (net of the loans), the total equity of the bank and the sum of households' liquidity is constant and equal to base money. This can be verified by manipulation of the following identity, retrieved, from the accounting framework table above

$$
E^{H}+E^{C}+E^{K}+E^{B}=\Delta+R^{b}+K
$$

To understand the behavior of the model it is important to understand how the total stock of money is shared among the sectors. If the money gets stuck in one of the sectors, the economic system is - broadly speaking - going out of equilibrium and a crisis emerges.

We start our tale from a near to full employment condition,around period 1200, in which consumptions firms, trying to keep their production capacity at the desired level, invest in new capital at full speed. The capital firms, observing a negative difference between production and perceived demand, will either increase the price or increase the desired production, depending on their position with respect to the average price. The increase in actual production might be constrained or hampered due to the tightness of the labor market. This implies that excess demand will push up the prices of capital goods, while capital production might increase less than desired. In the following period, the capital firms will still observe excess demand inducing more capital firms to increase their prices. A tight labor market, coupled with high demand for capital goods implies a spike in capital prices. The steep change in the price of capital goods implies an increase in the flow of money going from the consumption sector to the capital sector. As a consequence, the amount of money in the capital sector spikes just after the price increase (see figure 9). Consumption firms will increase the demand for credit to face the increased cost of the capital good. The share of money owned by the consumption sector turns negative (since they have also capital in their balance sheet this is not automatically making them bankrupt), the debt and leverage rise and the crisis begins, see figures 10 and 11 . 

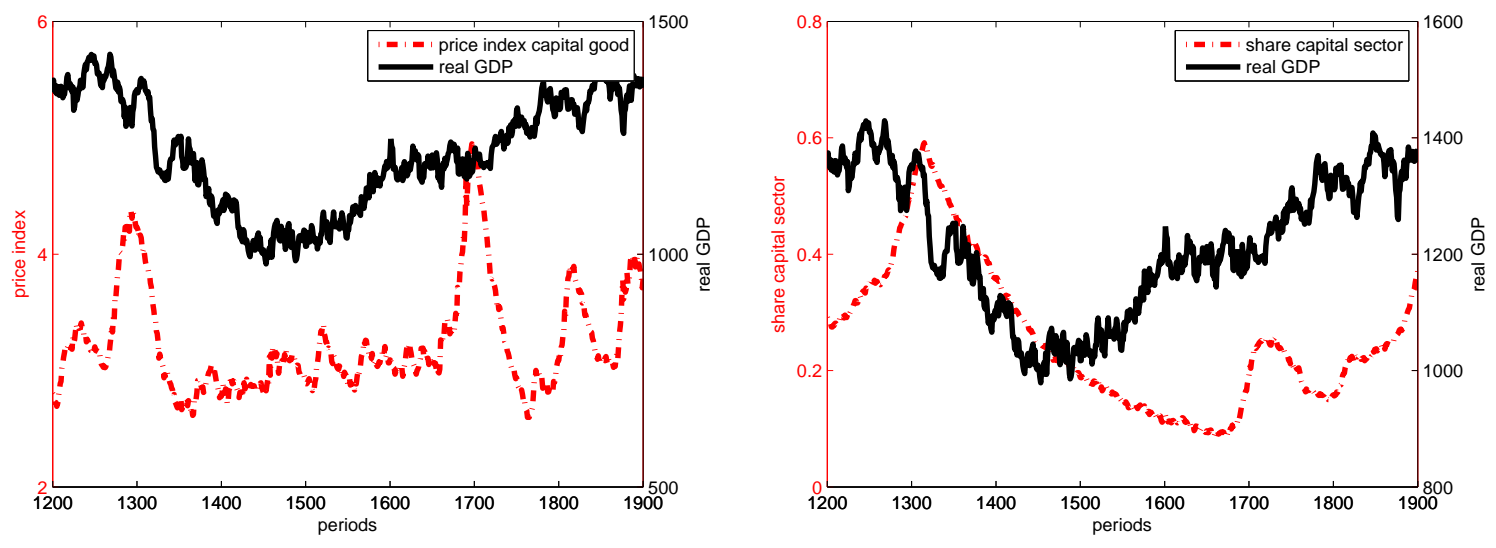

Figure 9: Right: Capital good price. Left: Share of total money in the capital sector, net of loans.
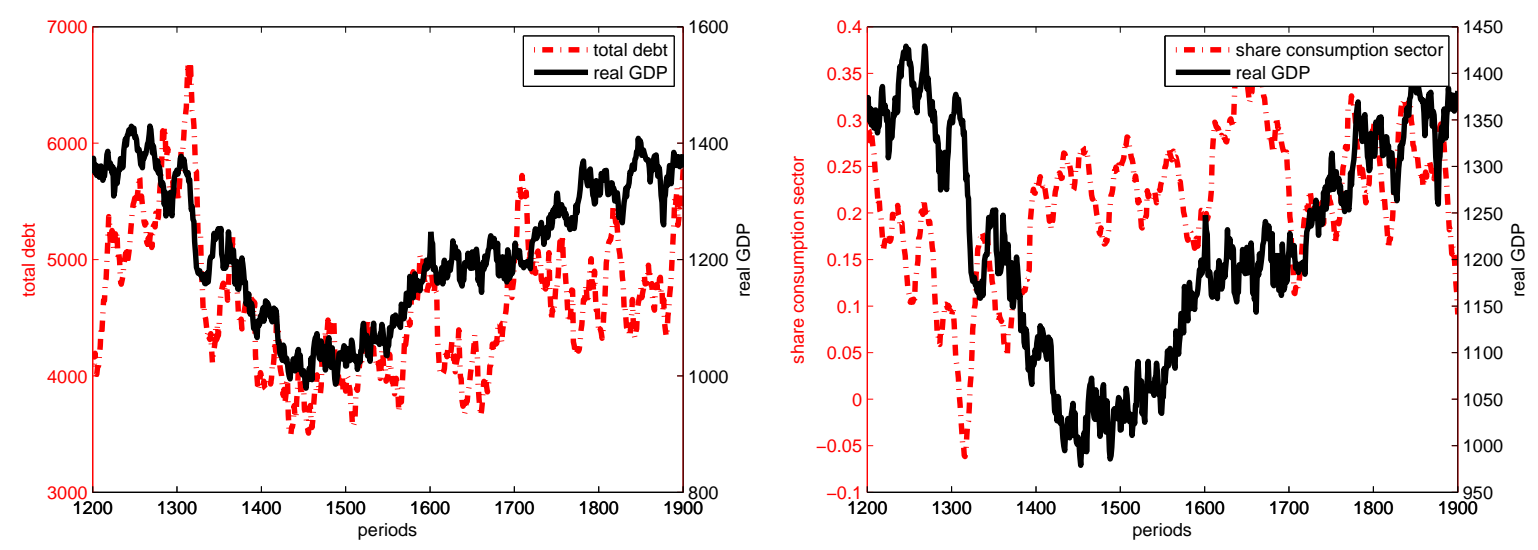

Figure 10: Right: Total debt in the consumption sector. Left: Share of total money in the capital sector, net of loans.
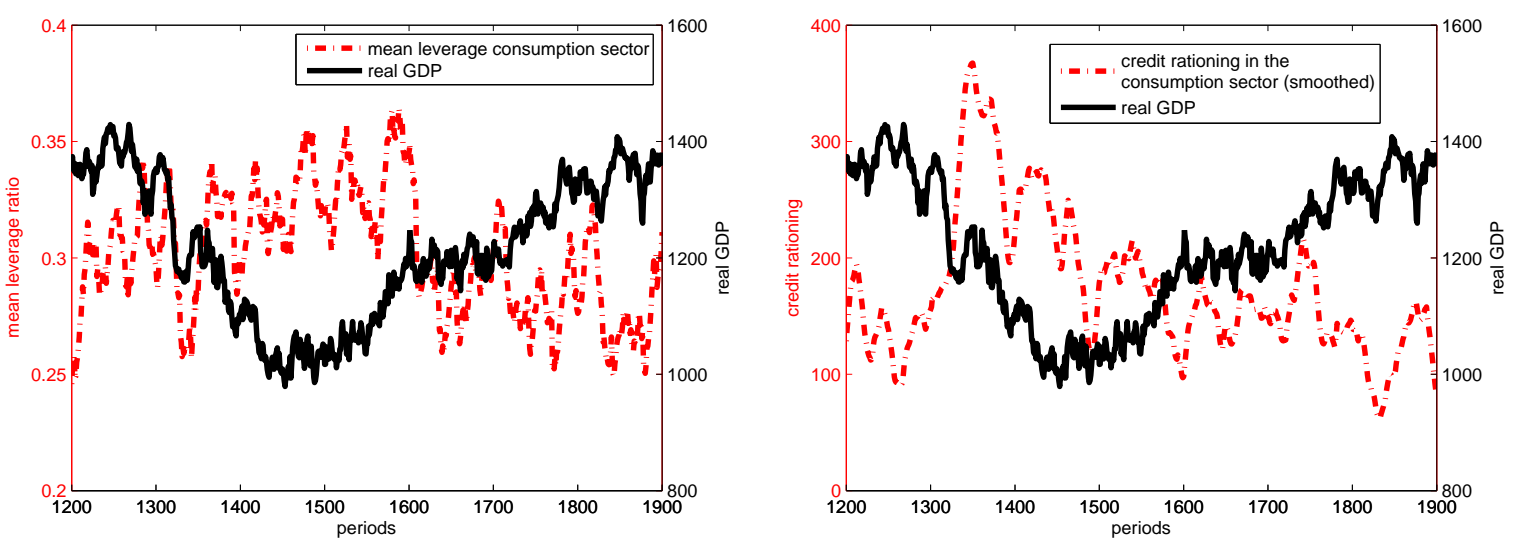

Figure 11: Right: mean leverage in the consumption sector. Left: credit rationing in the consumption sector (smoothed). 
With the increase of the leverage and the increase of debt, the credit rationing of the consumption firms increases (see left panel in figure 11). The debt of each single firm, together with the riskiness of the firm, is determining the maximum amount of new loans the bank is willing to loan to the firm. The credit rationing will reduce the liquidity available to the consumption firms, reducing the investments and consumption good production. The reduction in consumption firms' production implies a reduction in capital demand and a reduction in capital prices.

The consumption sector is the largest in the economic system, therefore a reduction in production in the consumption sector has a very strong effect on the overall GDP. The share of money in the consumption sector increases and the debt of the consumption firms reduces together with the reduction in production, the credit rationing is reduced, and the economy starts the recovering. It is interesting to note that there is a second spike in capital good prices during the recovery around period 1700, which is associated with a smaller spike in the share of money owned by the capital sector without triggering a crisis. The increase in the price of the capital good price is not alone responsible for the crisis. To trigger a huge and persistent economic downturn the increase in the price of capital goods has to be coupled with a high level of debt and low share of money owned by the consumption sector.

A crucial role to the emergence of a crisis in the model is played by the stock of debt in the economic system. We can use total credit to commercial and industrial sector to look at the relation between total debt and the economic performance in the observed data (as before we filter the time series using the hp filter and consider the cycle component). The left panel of figure 12 shows the correlation in time between lagged total debt and unemployment. The correlation structure confirms the story of the crisis, the debt in period $t-5$ is positively correlated with the unemployment in period $t$, meaning that a high debt implies a high unemployment in the future. The correlation is reversed when we consider future debt, meaning that high unemployment today implies on average low debt in the future. Essentially we are looking at the business cycle related to the debt cycle. The right panel of figure 12 shows the correlation in time between the observed lagged total debt (Commercial And Industrial Loans in FRED) and the 

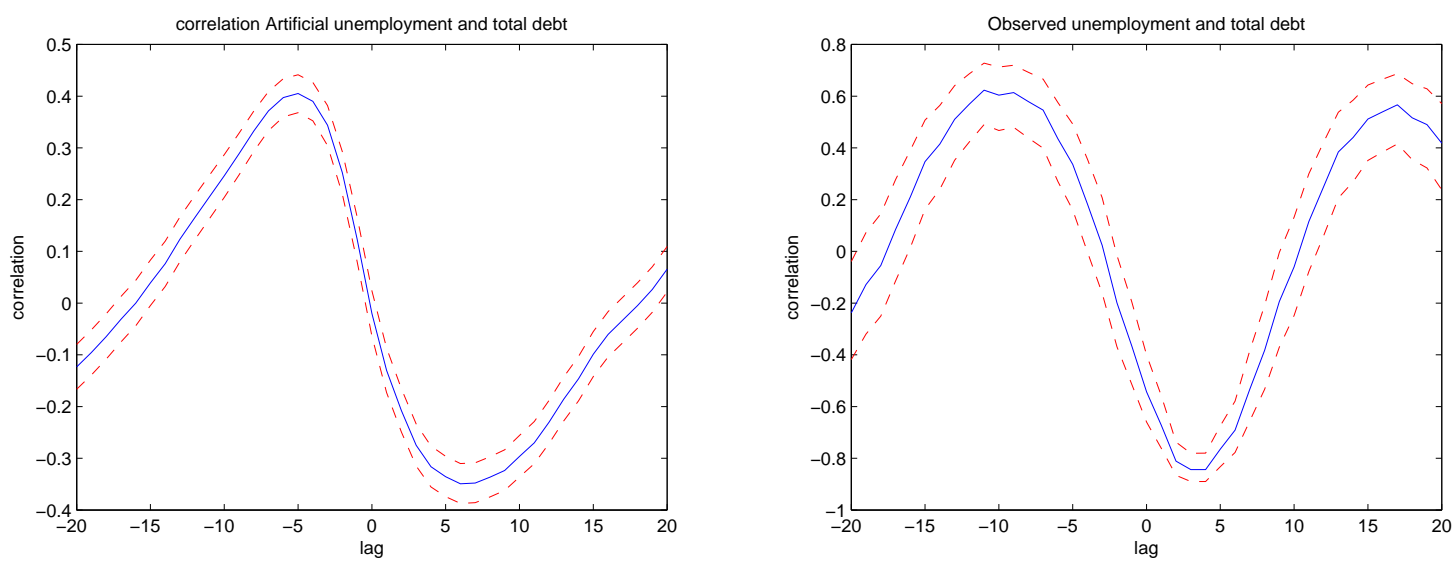

Figure 12: Right: Artificial Data. Correlation between the cycle component of the total debt lagged and the unemployment. Left: Observed Data. Correlation between the cycle component of the total debt lagged and the unemployment.
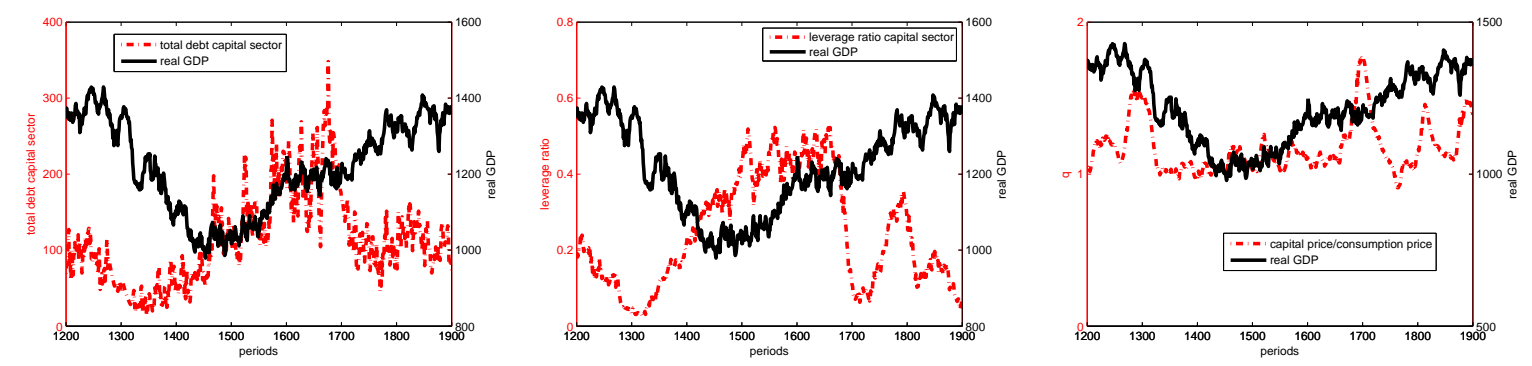

Figure 13: Right: Total debt in the capital sector. Center: mean leverage in the capital sector. Left: ratio between capital price and consumption price.

observed unemployment. It is very interesting to note how the observed correlation structure is qualitatively similar to the artificial correlation structure. The observed data confirm how the debt of the production sector can be used as a leading indicator with respect to the crisis, and that the crisis itself has the effect of reducing the debt.

The interactions between the production sectors and between the production sectors and the financial system creates the huge fluctuation and the crisis. Even if the upstream sector is relatively small with respect to the down stream sector, it is the responsible for triggering the crisis. The price decisions of the capital sector directly influences the cost of production and the financial fragility of the downstream sector. The downstream sector, due to its dimension, determines the output of the economic system. 


\subsection{Understanding how the emergent properties emerge}

A crucial criticism to standard equilibrium models is that they are not able to explain autocorrelation in observed time series without an exogenous autocorrelated shock. In this model, we show how autocorrelation in aggregate time series emerges from the micro level of the system without any exogenous aggregate shock. On the other hand, a crucial criticism of agent-based models is that it is usually very difficult to understand the mechanisms underlying the aggregate behavior of the model. In this section we try to shed some light on what is causing the autocorrelation and the emergence of crisis.

\begin{tabular}{|l|l|l|}
\hline Model set up & Crisis $^{31}$ & Autocorrelation \\
\hline Full model & $\boldsymbol{J}$ & 0.6863 \\
No Capital & $\boldsymbol{x}$ & 0.4728 \\
No Financial & $\boldsymbol{x}$ & 0.6645 \\
No capital \& No Capital & $\boldsymbol{x}$ & 0.4114 \\
\hline
\end{tabular}

Table 5: Adaptive Behavior. The results on the presence of a crisis and on the autocorrelation in the GDP time series for different set ups. To generate deep crisis we need the full model.

\begin{tabular}{|l|l|l|}
\hline Model set up & Crisis $^{32}$ & Autocorrelation \\
\hline Full model & $\boldsymbol{x}$ & 0.0988 \\
No Capital & $\boldsymbol{x}$ & 0.0647 \\
No Financial & $\boldsymbol{x}$ & -0.0080 \\
No capital \& No Capital & $\boldsymbol{x}$ & -0.0500 \\
\hline
\end{tabular}

Table 6: Random Behavior. The results on the presence of a crisis and on the autocorrelation in the GDP time series for different set ups. To generate deep crisis we need the full model.

The main ingredients of the model are the adaptive behavior and the presence of four distinct and interacting economic sectors: the financial sector, the upstream sector, the downstream sector and the household sector. To understand the effect of the different ingredients on the emerging properties of the economic system we switch off some of them. In particular we replace the adaptive behavior described above with a random behavior. Both the consumption firms and the capital firm will choose to produce a constant quantity with an i.i.d. error and sell at a constant price with an i.i.d error. This implies the absence of any feedback between behaviors, and between micro level and macro level. To switch off the capital sector without changing the model too deeply, we choose to keep the production functions as they are, i.e. the consumption firms are still 
going to use the capital good as an input. We assume that the capital is abundant and is always available for free ${ }^{33}$. To switch off the financial system we simply assume that the bank is considering all firms alike and risk free, and has infinite equity. In table 5 and table 6 the results of the different set up of the model, with what concerns the presence of crisis and autocorrelations. For each model we run 20 simulations with 3000 periods, discarding the first 1000. The unemployment of the models with adaptive behavior and without capital and/or financial system is very low and near full employment. The unemployment in the random behavior model depends on the distribution of random production and price.

The autocorrelation is crucially determined by the adaptive behavior and enhanced by the presence of the capital sector. In the models with random behavior the autocorrelation is very low while it is reduced when the behavior is adaptive but the capital sector is shut off. The emergence of a crisis needs the full model. As described in the previous section, a crisis emerge from the adaptive behavior, which is the responsible for the increase in capital good prices, and the interaction between the sectors. The adaptive behavior is intuitively introducing memory in the individual behavior, memory which is transferred to the aggregate time series. Moreover, the adaptive behavior is reacting to the environment, creating feedbacks between individual behavior, aggregate behavior and back to the individual behavior. These feedbacks are propagated through the system due to the interaction between the different economic sectors.

\section{Conclusions}

This paper presents and agent-based model with capital and credit. The model shows how important the upstream-downstream relation is for the emergence of crisis. The small upstream sector (K-firms) has a crucial influence on the balance sheet and on the production costs of the relatively big downstream sector (C-firms). The GDP is mostly determined by the production of consumption goods, but the production of the

\footnotetext{
${ }^{33}$ The capital value is an important item in consumption firms balance sheet. In the attempt of changing as little as possible we replace the capital value in the balance sheet with an item with constant value equal to the initial value of capital in the full model.
} 
consumption goods depends crucially on the upstream sector and on the financial system. The production relations have great importance in shaping the business cycle. The other important ingredients in the model are the behavioral assumptions. We suppose that the firms do not have perfect knowledge about the demand function and do not know the behavior of the other agents. To deal with the uncertainty, the firms adopt an adaptive behavior: they use past information to decide on prices and quantities. This is the crucial assumption both for the emergence of a crisis and for the properties of the aggregate time series. Experimental evidence has shown how human subjects faced with difficult choices and uncertain environment, tend to use simple heuristics to take decisions. The economic agents are not fully rational, they do not have full information, and even if they had full information they would not be able to process the whole information set. Simple adaptive heuristics are the most plausible assumption ex-ante, i.e. from the empirical evidence, and are also the most plausible assumption ex-post since they are crucial in reproducing a very well established stylized fact, i.e. the autocorrelation in the aggregate time series. This paper suggests that future research should keep looking at input-output relations and adaptive behaviors as crucial determinants of the business cycle. 


\section{References}

[1] Bernanke, B.S., M. Gertler, and S. Gilchrist (1999): "The Financial Accelerator in a Quantitative Business Cycle Framework". In Handbook of Macroeconomics, Volume 1, J.B. Taylor, and M. Woodford eds., 1341-1393.

[2] Bhaskar, V., S. Machin, and G.C. Reid (1993): "Price and Quantity Adjustment over the Business Cycle: Evidence from Survey Data". Oxford Economic Papers, 45(2), $257-268$.

[3] Carrol, C.D. (1992): "How does future income affect current consumption?". Working Paper Series / Economic Activity Section 126, Board of Governors of the Federal Reserve System (U.S.).

[4] Carrol, C.D. (1997): "Buffer-Stock Saving and the Life Cycle/Permanent Income Hypothesis". Quarterly Journal of Economics, 112(1), 1-55.

[5] Carrol, C.D. (2009): "Precautionary saving and the marginal propensity to consume out of permanent income". Journal of Monetary Economics, 56(6), 780-790.

[6] Christiano, L., R. Motta, and M. Rostagno (2010): "Financial Factors in Economic Fluctuations". Working Paper Series 2010-1192, European Central Bank.

[7] Cincotti, S., M. Raberto, an A. Teglio (2010): "Credit Money and Macroeconomic Instability in the Agent-based Model and Simulator Eurace". Economics: The OpenAccess, Open-Assessment E-Journal, 4(26).

[8] Clarida, R., J. Gali, an M. Gertler (1999): "Monetary Policy Rules and Macroeconomic Stability: Evidence and Some Theory". Quarterly Journal of Economics, $115(1), 147-180$.

[9] Dawid, H., S. Gemkow, P. Harting, S. van der Hoog, and M. Neugart (2011): "The Eurace@Unibi Model: An Agent-Based Macroeconomic Model for Economic Policy Analysis". mimeo.

[10] Deaton, A.S. (1991): "Saving and Liquidity Constraints". Econometrica, 59, 12211248. 
[11] Delli Gatti, D., M. Gallegati, P. Cirillo, S. Desiderio, and E. Gaffeo (2011): "Macroeconomics from the Bottom-up". Springer.

[12] Dosi, G., G. Fagiolo, and A. Roventini (2010): "Schumpeter meeting Keynes: A Policy-Friendly Model of Endogenous Growth and Business cycles". Journal of Economic Dynamic and Control, 34(9), 1748-1767.

[13] Gertler, M. and N. Kiyotaki (2010): "Financial Intermediation and Credit Policy in Business Cycle Analysis". In Handbook of Monetary Economics, Volume 3, B.M. Friedman, and M. Woodford eds., 547-599.

[14] Kawasaki, S., J. McMillan, and K.F. Zimmerman (1982): "Disequilibrium Dynamics: An Empirical Study". American Economic Review, 72(5), 992-1004 